\title{
Cortical Representation of Interaural Time Difference Is Impaired by Deafness in Development: Evidence from Children with Early Long-term Access to Sound through Bilateral Cochlear Implants Provided Simultaneously
}

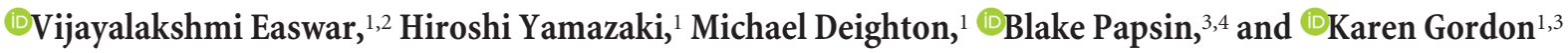 \\ ${ }^{1}$ Archie's Cochlear Implant Laboratory, Hospital for Sick Children, Toronto, Ontario M5G 1X8, Canada, ${ }^{2}$ Collaborative Program in Neuroscience, University \\ of Toronto, Toronto, Ontario M5S 1A8, Canada, ${ }^{3}$ Department of Otolaryngology, University of Toronto, Toronto, Ontario M5G 2N2, Canada, and \\ ${ }^{4}$ Department of Otolaryngology, Hospital for Sick Children, Toronto, Ontario M5G 1X8, Canada
}

Accurate use of interaural time differences (ITDs) for spatial hearing may require access to bilateral auditory input during sensitive periods in human development. Providing bilateral cochlear implants (CIs) simultaneously promotes symmetrical development of bilateral auditory pathways but does not support normal ITD sensitivity. Thus, although binaural interactions are established by bilateral CIs in the auditory brainstem, potential deficits in cortical processing of ITDs remain. Cortical ITD processing in children with simultaneous bilateral CIs and normal hearing with similar time-in-sound was explored in the present study. Cortical activity evoked by bilateral stimuli with varying ITDs $(0, \pm 0.4, \pm 1 \mathrm{~ms})$ was recorded using multichannel electroencephalography. Source analyses indicated dominant activity in the right auditory cortex in both groups but limited ITD processing in children with bilateral CIs. In normal-hearing children, adult-like processing patterns were found underlying the immature P1 ( $\sim 100 \mathrm{~ms})$ response peak with reduced activity in the auditory cortex ipsilateral to the leading ITD. Further, the left cortex showed a stronger preference than the right cortex for stimuli leading from the contralateral hemifield. By contrast, children with CIs demonstrated reduced ITD-related changes in both auditory cortices. Decreased parieto-occipital activity, possibly involved in spatial processing, was also revealed in children with CIs. Thus, simultaneous bilateral implantation in young children maintains right cortical dominance during binaural processing but does not fully overcome effects of deafness using present $\mathrm{CI}$ devices. Protection of bilateral pathways through simultaneous implantation might be capitalized for ITD processing with signal processing advances, which more consistently represent binaural timing cues.

Key words: beamformer; hearing loss; right dominance; simultaneous bilateral cochlear implant; source localization; spatial processing

Significance Statement

Multichannel electroencephalography demonstrated impairment of binaural processing in children who are deaf despite early access to bilateral auditory input by first finding that foundations for binaural hearing are normally established during early stages of cortical development. Although 4- to 7-year-old children with normal hearing had immature cortical responses, adult patterns in cortical coding of binaural timing cues were measured. Second, children receiving two cochlear implants in the same surgery maintained normal-like input from both ears, but this did not support significant effects of binaural timing cues in either auditory cortex. Deficits in parieto-occiptal areas further suggested impairment in spatial processing. Results indicate that cochlear implants working independently in each ear do not fully overcome deafness-related binaural processing deficits, even after long-term experience.

\section{Introduction}

Detecting differences in the time of arrival of sound in both ears helps locate a sound source and understand speech in noise. Sen-

Received Aug. 9, 2016; revised Dec. 21, 2016; accepted Jan. 18, 2017

Author contributions: V.E., M.D., B.P., and K.G. designed research; V.E., H.Y., M.D., and K.G. performed research;

V.E., H.Y., and K.G. contributed unpublished reagents/analytic tools; V.E. and K.G. analyzed data; V.E., H.Y., M.D.,

B.P., and K.G. wrote the paper. sitivity to interaural time differences (ITDs) on the order of $50-70 \mu$ s is observed in typically developing 4 - to 7-month-old infants (Ashmead et al., 1991) and improves with age (median $12.5 \mu$ s in adults) (Van Deun et al., 2009). Changes in both sen-

This work was supported by Restracomp fellowship to V.E. and Canadian Institute for Health Research to K.G. We thank Melissa Polonenko for assistance with preliminary data collection; and Daniel Wong, Salima Jiwani, and Carmen McKnight for response analysis.

The authors declare no competing financial interests. 
sory (neural encoding) and nonsensory (e.g., attention) components could contribute to development of ITD sensitivity and/or its evaluation (Van Deun et al., 2009; Litovsky, 2012); thus, we aimed to identify cortical (sensory) representation of ITDs in normal-hearing children and determine whether that was promoted in children with deafness who had access to sound through bilateral cochlear implants (CIs) from young ages.

Cortical processing of ITDs is supported by near-field data in animals (Werner-Reiss and Groh, 2008; Lee and Middlebrooks, 2011) and imaging in human adults demonstrating contralateral processing of leading ITDs (McEvoy et al., 1993; Krumbholz et al., 2005; Johnson and Hautus, 2010). Some human studies also report hemispheric asymmetry in contralaterality with similar sensitivity of the right hemisphere to spatial cues in both hemifields as opposed to more restricted right hemifield preference of the left hemisphere (Krumbholz et al., 2005; Magezi and Krumbholz, 2010; Briley et al., 2013). Because children show mature ITD perception by 5 years of age (Litovsky, 1997; Van Deun et al., 2009), we hypothesized that adult patterns of ITD coding in the cortex are present in normal-hearing children and that access to these cues could be established in children with deafness through early bilateral cochlear implantation.

Early-onset deafness impairs ITD sensitivity in the inferior colliculus (IC) (Hancock et al., 2010, 2013) and reduces the number of cortical neurons coding ITDs (Tillein et al., 2010, 2016), but the basic pathways remain preserved. Although longer duration of deafness leads to poorer ITD tuning, the effects of early-onset deafness on ITD sensitivity are more detrimental than late-onset deafness (Hancock et al., 2013). Symmetrical development of bilateral pathways can be promoted through early $(<3$ years of age) and bilateral implantation with limited interimplant delay (Papsin and Gordon, 2008). Binaural brainstem interactions in children with bilateral CIs confirm tonotopic registration of bilateral input (Gordon et al., 2012); however, representations of binaural activity more centrally have not been explored in these children. Behavioral findings suggest that abnormalities in binaural perception may be present. ITD perception was initially considered to be deficient in children using bilateral CIs (Salloum et al., 2010); however, detection of these cues in a lateralization task emerged in cohorts with long-term bilateral CI use (Gordon et al., 2014). The inability by a similar cohort to perceive these bilateral stimuli as a fused image (Steel et al., 2015) might reflect compensatory mechanisms to perform the lateralization task with a diffused image. This altered mechanism may be in response to the deficits in passive sensory processing of binaural timing cues. Moreover, whereas children who received CIs simultaneously demonstrated equal sensitivity to right and left leading stimuli, children who received CIs sequentially demonstrated a bias toward the first implanted CI, potentially reflecting abnormal aural preference consequent to prolonged unilateral CI stimulation (Gordon et al., 2015).

Using multichannel electroencephalogram (EEG) in the present study, normal-hearing children were found to exhibit mature cortical ITD patterns from an early age of 4 years, consistent with adult behavioral performance at this age. This was supported by right hemispheric dominance during binaural processing, higher activity for contralateral leading ITDs in each hemisphere, and

Correspondence should be addressed to Dr. Vijayalakshmi Easwar, Neurosciences and Mental Health, Archie's Cochlear Implant Laboratory, Room 6D08, Hospital for Sick Children, 555 University Avenue, Toronto, Ontario M5G 1X8, Canada. E-mail: v.easwar@utoronto.ca.

DOI:10.1523/JNEUROSCI.2538-16.2017

Copyright $\odot 2017$ the authors $\quad 0270-6474 / 17 / 372350-13 \$ 15.00 / 0$
Table 1. Demographic data ${ }^{a}$

\begin{tabular}{|c|c|c|c|c|c|}
\hline & $\begin{array}{l}\text { Etiology/risk } \\
\text { factor }\end{array}$ & $\begin{array}{l}\text { Age at } \\
\text { test (yr) }\end{array}$ & $\begin{array}{l}\text { Age at } \\
\text { implant (yr) }\end{array}$ & $\begin{array}{l}\text { Time-in-sound } \\
\text { (yr) }\end{array}$ & $\begin{array}{l}\text { Bilateral Cl } \\
\text { experience (yr) }\end{array}$ \\
\hline \multicolumn{6}{|l|}{ Cl participant } \\
\hline Cl1 & Unknown & 5.84 & 2.70 & 3.15 & 3.15 \\
\hline $\mathrm{Cl} 2$ & Family history & 5.29 & 3.26 & 2.04 & 2.04 \\
\hline $\mathrm{Cl} 3$ & $\begin{array}{l}\text { Enlarged vestibular } \\
\text { aqueduct }\end{array}$ & 6.58 & 2.85 & 3.73 & 3.73 \\
\hline $\mathrm{Cl} 4$ & $\begin{array}{l}\text { Incomplete partition } \\
\text { Type II }\end{array}$ & 5.25 & 3.16 & 3.52 & 2.09 \\
\hline $\mathrm{Cl} 5$ & Unknown & 5.88 & 2.36 & 3.52 & 3.52 \\
\hline $\mathrm{Cl} 6$ & Unknown & 5.44 & 1.20 & 5.04 & 4.24 \\
\hline $\mathrm{Cl} 7$ & Unknown & 6.90 & 2.83 & 4.07 & 4.07 \\
\hline $\mathrm{Cl} 8$ & Premature birth & 5.77 & 1.12 & 4.65 & 4.65 \\
\hline $\mathrm{Cl} 9$ & Unknown & 5.17 & 1.04 & 4.12 & 4.12 \\
\hline $\mathrm{Cl} 10$ & $\begin{array}{l}\text { Congenital } \\
\text { cytomegalovirus } \\
\text { infection }\end{array}$ & 5.17 & 1.06 & 4.11 & 4.11 \\
\hline $\mathrm{Cl} 11$ & Unknown & 7.36 & 3.49 & 5.13 & 3.87 \\
\hline $\mathrm{Cl} 12$ & $\begin{array}{l}\text { Low birth weight/ } \\
\text { NICU stay }\end{array}$ & 6.09 & 1.09 & 4.99 & 4.99 \\
\hline $\mathrm{Cl} 13$ & Family history & 6.85 & 1.82 & 5.03 & 5.03 \\
\hline $\mathrm{Cl} 14$ & Unknown & 7.40 & 3.12 & 4.95 & 4.33 \\
\hline $\mathrm{Cl} 15$ & Connexin26 & 7.08 & 1.05 & 6.03 & 6.03 \\
\hline $\mathrm{Cl} 16$ & Unknown & 5.98 & 1.38 & 4.61 & 4.61 \\
\hline \multicolumn{6}{|l|}{ Group } \\
\hline $\begin{array}{l}\text { Normal } \\
\text { hearing }\end{array}$ & $N=16$ & $5.24(0.95)$ & NA & $5.24(0.95)$ & NA \\
\hline Bilateral Cls & $N=16$ & $6.13(0.79)$ & $2.10(0.95)$ & $4.29(0.97)$ & $4.04(1.02)$ \\
\hline
\end{tabular}

hemispheric asymmetry for right versus left leading ITDs. We also demonstrate that normal-like right dominance during binaural processing can be established in children with deafness through the recommended clinical standard of early and simultaneous provision of two CIs (Ramsden et al., 2012). Nonetheless, this was accompanied by poor ITD sensitivity and limited hemispheric differences, suggesting that sensory coding of ITDs continues to be impaired even with long-term bilateral CI use.

\section{Materials and Methods}

The study protocol (\#100000294) was approved by the Research Ethics Board at the Hospital for Sick Children and conforms to the Tri-Counsel Policy on the Ethical Conduct for Research Innovation. Written parent consent was obtained before data collection.

Participants. Children who received their two CIs (Cochlear's Nucleus 24 devices) in the same surgery at $<3.5$ years of age with $>2$ years of $\mathrm{CI}$ experience were invited to participate in the study. Participants were 16 children (12 boys). Etiology/risk factor of deafness, age at test, age at implant, and hearing experience for each child as well as group mean demographic information are provided in Table 1 . All 16 children had prelingual hearing loss, which was additionally progressive in CI4. On average, children had $4.04 \pm 1.02$ years of bilateral CI experience at the time of data collection. Most children wore hearing aids before implantation and, together with minimal useable residual hearing with hearing aids (aided threshold of $\leq 40 \mathrm{~dB} \mathrm{HL}$ at a minimum of one frequency between $0.5-4 \mathrm{kHz}$ ), had an average of $4.29 \pm 0.97$ years of time-insound (length of hearing experience). To evaluate cortical coding of ITD cues in children with normal hearing and to compare the development of cortical processing in children with bilateral CIs, 16 children (9 boys) with normal hearing with similar time-in-sound (assumed equivalent to their chronological age) were recruited (Fig. 1). Parents reported no complaints of ear, hearing, or neurological disorders/symptoms. Because children with normal hearing were matched for time-in-sound, their average chronological age was lower than the CI group by 0.89 years $\left(t_{(29)}=\right.$ $-2.88, p=0.007)$. Although the range of time-in-sound overlapped 
Normal Hearing Bilateral Cls

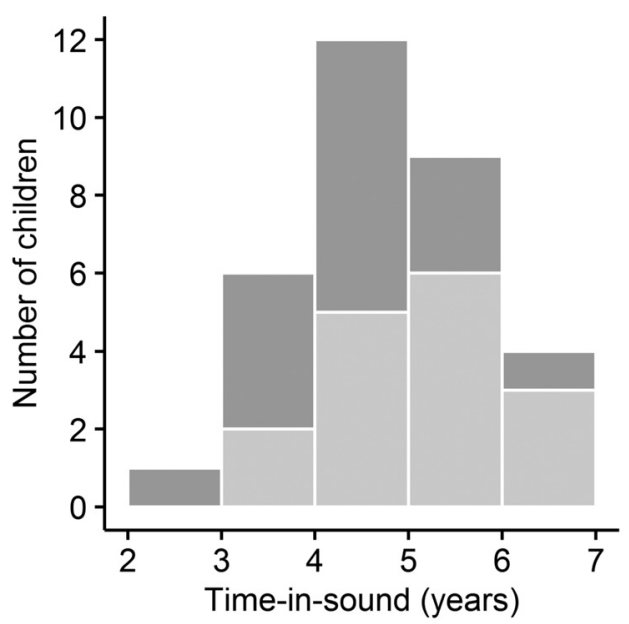

Figure 1. Children in both groups had similar time-in-sound (in years) at the time of data collection.

almost entirely between the two groups (Fig. 1), children with CIs had a small yet significantly shorter time-in-sound experience by an average of $<1$ year (Table $\left.1 ; t_{(29)}=2.78, p=0.009\right)$. Younger children with normal hearing could not be tested due to reduced compliance with testing, and older children with CIs with longer time-in-sound were not included as they tended to show more mature cortical responses (emerging P1N1-P2 morphology) rather than an immature response (characterized by P1-N2; see Fig. $3 A$ ). The evolution from the immature to mature waveform has been clearly described, beginning as early as 8 years of age (Moore and Guan, 2001; Ponton and Eggermont, 2007). Any deviation from an immature response was excluded to avoid potential confounds in interpretation.

Stimuli. In children with CIs, biphasic electrical pulses with a width of $25 \mu \mathrm{s} /$ phase were delivered bilaterally to the electrode \#20 pair (apical end) at 250 pulses/s using SPEAR3 (Hearworks). In children with normal hearing, clicks with a duration of $100 \mu$ s were delivered bilaterally using Etymotic ER-3A coupled with a foam tip at 250 clicks/s. Stimulus trains were $36 \mathrm{~ms}$ long presented at a constant rate of 1 train/s. Similar to previous studies (Gordon et al., 2013; Jiwani et al., 2016; Easwar et al., 2017), in children with CIs, stimulus levels were set at 10 manufacturerdefined clinical units $(\mathrm{CU} ; 10 \mathrm{CU}=20.96 \mu \mathrm{A} ; 6.79 \mathrm{~dB}$ re $100 \mu \mathrm{A})$ below those necessary to elicit equal amplitude brainstem responses when either CI was individually stimulated. Levels were further adjusted to perceptually matched levels (Gordon et al., 2016) if levels based on brainstem responses were not balanced. In children with normal hearing, click trains were presented at $50 \mathrm{~dB}$ above behavioral threshold in each ear. This was perceptually balanced between the ears. At constant stimulus levels, five conditions with varying ITDs were evaluated (Fig. 2). The onset of stimulus trains was delayed by 0.4 and $1 \mathrm{~ms}$ in either the left or the right ear/CI creating an interaural time difference. A condition with synchronized onset (Bil-0, 0 ITD) was also evaluated (Fig. 2). The ITD conditions chosen are similar to those used in a previous study (Gordon et al., 2014) which evaluated behavioral responses of lateralization in a similar cohort of children who received their CIs simultaneously with $\sim 4$ years of bilateral CI experience on average. As in that study, the normalhearing control group in the present study listened to click trains. Clicks closely resemble onset characteristics of electric pulses (e.g., Khosla et al., 2003) and have more consistent contralaterally increased cortical activity from left or right monaural stimulation than tonebursts in young children with normal hearing (Yamazaki et al., unpublished observation). Thus, clicks were used to maximize chances of measuring changes in lateralization with ITDs. Throughout this study, the leading side is indicated either by the side in which the stimulus arrived earlier (right [R-1 ms, R-0.4 ms] and left [L-1 ms, L-0.4 ms]; Fig. 2) or described in terms of

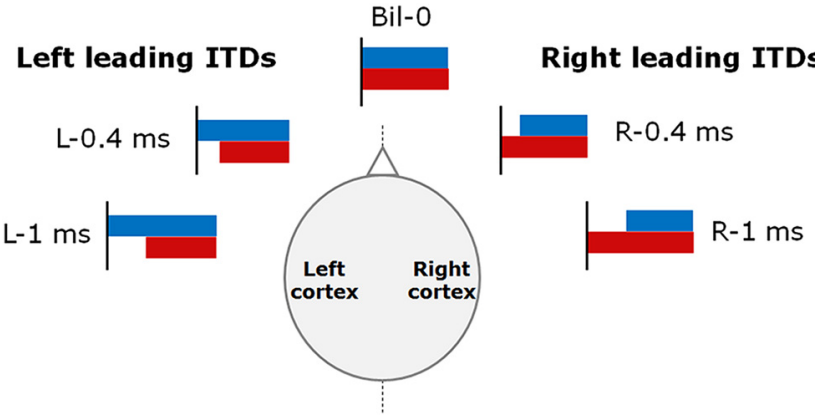

Figure 2. Five bilateral conditions evaluated. Red bars represent the onset (magnified) of 36 $\mathrm{ms}$ pulse/click trains presented to the right ear/Cl (length truncated). Blue bars represent the onset (magnified) of $36 \mathrm{~ms}$ pulse/click trains presented to the left ear/CI (length truncated). $R$, right leading ITDs; L, left leading ITDs. Position around schematic head is arbitrary for illustrative purposes.

leading side with reference to each hemisphere (ipsilateral [I-1 ms, I-0.4 $\mathrm{ms}$ ] and contralateral [C-1 ms, C-0.4 ms]).

Response recording. EEG activity in response to the five bilateral conditions was recorded using a 64-channel electrode cap worn by the child. During the recording, children sat in a sound booth and watched a silent movie with subtitles, read a book, or engaged in games/visual distractions requiring minimal movement. EEG, referenced to the right ear lobe, was recorded using a Synamps-II amplifier and the Scan version 4.5 software (Compumedics). EEG was sampled at $1000 \mathrm{~Hz}$ and bandpass filtered $(0.15-100 \mathrm{~Hz})$ during recording. Each $1000 \mathrm{~ms}$ epoch included a prestimulus baseline of $200 \mathrm{~ms}$. Epochs with EEG exceeding $\pm 100 \mu \mathrm{V}$ at the vertex electrode were removed before source localization. Two replicated averages with a minimum of 100 epochs each were obtained per condition.

Localization of cortical activity. The Time Restricted, Artifact and Coherence source Suppression (TRACS) beamformer (details described by Wong and Gordon, 2009; Gordon et al., 2013; Jiwani et al., 2016) was used to localize cortical activity in each condition for each response peak (P1/Pci and N2; see Fig. 3A,B). In brief, the TRACS uses an adaptive spatial filter (linearly constrained minimum variance type) on the average-referenced EEG bandpass filtered between 1 and $30 \mathrm{~Hz}$ to estimate dipole activity in $\sim 64,000$ voxels of dimensions $3 \times 3 \times 3 \mathrm{~mm}$. Dipole activity was computed using an age-appropriate MNI head model template created using the Template-O-matic toolbox (Wilke et al., 2008). Head model templates were used because the surgically placed magnet in children with CIs is a contraindication for MRI. A 3-layer boundary element model mesh was created based on the head model template to simulate geometry of the brain volume, skull and scalp, and their respective conductivities. Source activity in each hemisphere underlying each response peak was evaluated by suppressing the other hemisphere (Dalal et al., 2006). In children with CIs, an artifact suppression algorithm was used to suppress the CI-generated artifact (Wong and Gordon, 2009). This validated algorithm estimates the artifact space based on activity between -80 and $10 \mathrm{~ms}$ (re stimulus onset) in an epoch and suppresses up to $97 \%$ of the CI artifact without distorting the response beyond the stimulus duration (Wong and Gordon, 2009). A pseudo-Z statistic, computed as the ratio of sample signal mean and SD of the prestimulus baseline ( -200 to $-80 \mathrm{~ms}$ re stimulus onset), was used to normalize activity in each voxel. A threshold pseudo- $Z$ was determined based on a one-tailed omnibus test (Petersson et al., 1999) using a \pm average that cancelled out time-locked signals (Gordon et al., 2013). The threshold pseudo- $Z$ represented baseline activity and therefore enabled isolation of voxels with activity above baseline (Jiwani et al., 2016; Easwar et al., 2017; Yamazaki et al., unpublished observation). A pseudo-Z map, which plotted the threshold-corrected pseudo- $Z$ per voxel on MNI head model templates, was generated to localize cortical activity within each hemisphere. Axial views are shown in Figure 5. The lower end of the scale in blue represents below-baseline activity, whereas the higher end in warmer colors represents hotspots of stimulus-evoked abovebaseline activity. The time window surrounding each peak was individually 
chosen for each condition based on the $\mathrm{Cz}$ waveforms (see Fig. 3A) and global field power (GFP) (see Fig. 3B).

Peak dipole activity and latency. Consistently activated cortical areas in each condition were identified using group averages of thresholdcorrected pseudo-Z maps (see Fig. 5A,D). Signals were clearest in left and right temporal lobes as expected in response to sound and consistent with sound-evoked regions measured in other cohorts of children and adolescents using the TRACS beamformer (Gordon et al., 2013; Jiwani et al., 2016; Easwar et al., 2017; Yamazaki et al., unpublished observation) as well as in adults using other imaging technologies (e.g., Krumbholz et al., 2005, 2007; Johnson and Hautus, 2010; McLaughlin et al., 2016). Left and right auditory cortices were defined by MNI coordinates $(x \leq-55$, $-35 \leq y \leq 5$ and $-10 \leq z \leq 20 \mathrm{~mm}$ for the left auditory cortex and $x \geq 55$, $-35 \leq y \leq 5$ and $-10 \leq z \leq 20 \mathrm{~mm}$ for the right auditory cortex as in previous studies) (Jiwani et al., 2016; Easwar et al., 2017; Yamazaki et al., unpublished observation). The voxel with the highest pseudo- $Z$ in the defined region of interest within each hemisphere was identified as the peak dipole for each condition. The source locations of P1/Pci peak dipoles across all conditions are shown in Fig. 4. Variance in source location around the mean was $10.21 \pm 4.64 \mathrm{~mm}$ for P1/Pci and $10.69 \pm$ $5.03 \mathrm{~mm}$ for N2. The dipole moment and associated latency of the peak dipole were used for statistical analysis and calculation of cortical lateralization and lead-side weighting indices. Consistency of the peak dipole moment and latency values were verified in voxels with the top 10 threshold-corrected pseudo- $Z$ values.

For each condition, a cortical lateralization index was calculated to measure the change in balance between right and left hemispheric activity. A normalized difference in hemisphere-specific peak dipole moment was obtained using the formula: ((right hemisphere - left hemisphere)/ (right hemisphere + left hemisphere) $) \times 100$ ) (Gordon et al., 2013; Jiwani et al., 2016). Values can range from $-100 \%$ to $100 \%$, the scale limits representing completely left to completely right lateralized activity with $0 \%$ representing balanced activity between the hemispheres. There were rare cases ( $n=4$ of $320 \mathrm{P} 1 /$ Pci peak dipoles and 7 of 320 N2 peak dipoles) in which the pseudo- $Z$ of the identified peak dipole in one auditory cortex was not above the threshold-pseudo- $Z$, but this was never observed in both auditory cortices for the same condition. The small dipole moment $(<4 \mathrm{nAm}$; mean $\pm \mathrm{SD}, 2.01 \pm 0.92 \mathrm{nAm})$ of below-baseline peak dipoles indicated low activity in one hemisphere and therefore a high degree of cortical lateralization. The associated peak dipole moment was included for statistical analyses; however, the associated peak latencies were not, as this may vary more randomly.

A normalized lead-side weighting index was computed for each hemisphere to evaluate the degree of left versus right hemifield preference accounting for the possible bias of hemispheric dominance (i.e., larger dipole moments in one hemisphere) (Briley et al., 2013). At each ITD (see Fig. $7 A$ ), the degree of right-lead weighting was obtained using peak dipole moment elicited in right leading conditions ([right leading/(right leading + left leading) $] \times 100$ ) and the degree of left-lead weighting was obtained using the peak dipole moment elicited in the left leading conditions ([left leading/(right + left leading) $] \times 100)$.

Permutation analyses. Because auditory spatial processing involves nonauditory areas (Griffiths et al., 1998; Weeks et al., 1999; Ducommun et al., 2002; Brunetti et al., 2005), activity in all voxels was compared using a between-group permutation analysis. Two-sided unpaired comparisons were used to compare differences in peak dipole moment voxelby-voxel between normal-hearing children and children with CIs in each condition using 10,000 permutations (Blair and Karniski, 1993; Chau et al., 2004). A Bonferroni correction $(p=0.05 / 62$ recording electrodes $=$ 0.0008 ) was applied to counteract inflation of the false-positive rate due to multiple comparisons (Jiwani et al., 2016).

Statistical analyses. GFP peak amplitude and latency for P1/Pci and N2 were compared using two-way (condition, group) mixed ANOVA. Three-way (condition, hemisphere, and group) mixed ANOVAs were performed on dipole moment and latency of P1/Pci and N2 response peaks to evaluate the effects of ITD in each group. A two-way mixed ANOVA, with condition as the within-subject factor and group as the between-subject factor, was conducted to evaluate differences in cortical lateralization. A four-way mixed ANOVA with hemifield, ITD, and hemisphere as within-subject factors and group as the between-subject factor was performed to evaluate hemispheric differences in lead-side weighting. Greenhouse-Geisser corrected degrees of freedom were used when sphericity was violated. Post hoc analyses included two-tailed paired $t$ tests. False discovery rate was used to counteract multiple comparison bias on false-positive rates (Benjamini and Hochberg, 1995). Corrected $p$ values are reported in this manuscript; values $<0.05$ were considered significant. Statistical analyses were performed using R (version 3.1.3 R core Team, 2013).

\section{Results}

Children with normal hearing, as well as bilateral CIs, demonstrated similar cortical development evidenced by comparable immature response morphology (Fig. 3A), consistent with the same range of time-in-sound between groups. The biphasic response, characterized by a dominant positive peak ( $\mathrm{P} 1$ in children with normal hearing and Pci in children with CIs) followed by a negative peak N2 (grand average $\mathrm{Cz}$ waveforms shown in Fig. $3 A$ ), is consistent with previous studies in young children (Ponton et al., 2000, 2002; Gordon et al., 2013). The mean GFP consisted of two corresponding peaks in both groups (Fig. 3B). GFP peak amplitude and latency of $\mathrm{P} 1 / \mathrm{Pci}$ and $\mathrm{N} 2$ are provided in Table 2. Two-way mixed ANOVA (condition $\times$ group) revealed a significant main effect of group for P1 $\left(F_{(1,30)}=15.92, p<\right.$ $0.001)$ and $\mathrm{N} 2\left(F_{(1,30)}=25.50, p<0.001\right)$ GFP peak amplitude, with higher amplitudes in children with CIs. GFP peak latencies were similar between groups $\left(\mathrm{P} 1 / \mathrm{Pci}: F_{(1,30)}=0.89, p=0.35 ; \mathrm{N} 2\right.$ : $\left.F_{(1,30)}=0.58, p=0.45\right)$. No main or interaction effects of condition were found for GFP amplitude and latency $(p>0.05)$. Topographical plots illustrating the spatial distribution of average-referenced surface EEG at peak GFPs are shown in Figure $3 C$. The effects of ITD during P1/Pci and $\mathrm{N} 2$ are quantified and interpreted based on the following source data from each hemisphere.

The accuracy of source localization using the TRACS beamformer relative to MEG has been measured as $15.3 \mathrm{~mm}$ in a small sample of individuals with normal hearing listening to pure tones (Wong, 2012) but can vary across individuals depending on deviations from template head models. In the present study, auditory evoked activity localized to the same left and right temporal areas as in previous studies in children (Gordon et al., 2013; Jiwani et al., 2016) and adults (Krumbholz et al., 2005, 2007; Johnson and Hautus, 2010; McLaughlin et al., 2016). Peak dipoles were chosen within two defined regions of interest (Fig. 4) that varied by an average $( \pm S D)$ of $10.21 \pm 4.64 \mathrm{~mm}$ for P1/Pci and $10.69 \pm 5.03 \mathrm{~mm}$ for N2 within subjects across the 5 ITD conditions.

\section{Right hemispheric dominance of cortical activity is evident in both groups, but sensitivity to ITD changes is impaired in children with CIs}

Mean peak dipole moment values in Figure $5 A$ illustrate higher activity in the right relative to the left hemisphere in both groups. This similarity between groups in right hemispheric dominance, when averaged across all bilateral conditions, is evident in Figure $5 B$. The difference in overall activity between hemispheres was confirmed by a significant main effect of hemisphere $\left(F_{(1,30)}=\right.$ 9.29, $p=0.005$ ) in the three-way ANOVA (hemisphere, condition, group). Pooled across groups and conditions (nonsignificant group $\times$ hemisphere interaction, $F_{(1,30)}=1.43, p=0.24$; nonsignificant group $\times$ condition $\times$ hemisphere interaction, $\left.F_{(4,120)}=0.08, p=0.99\right)$, activity in the right auditory cortex (mean $\pm \mathrm{SD}, 13.01 \pm 7.67 \mathrm{nAm}$ ) was significantly higher than in the left $(10.14 \pm 7.47 \mathrm{nAm})$. The overall activity was similar 
A

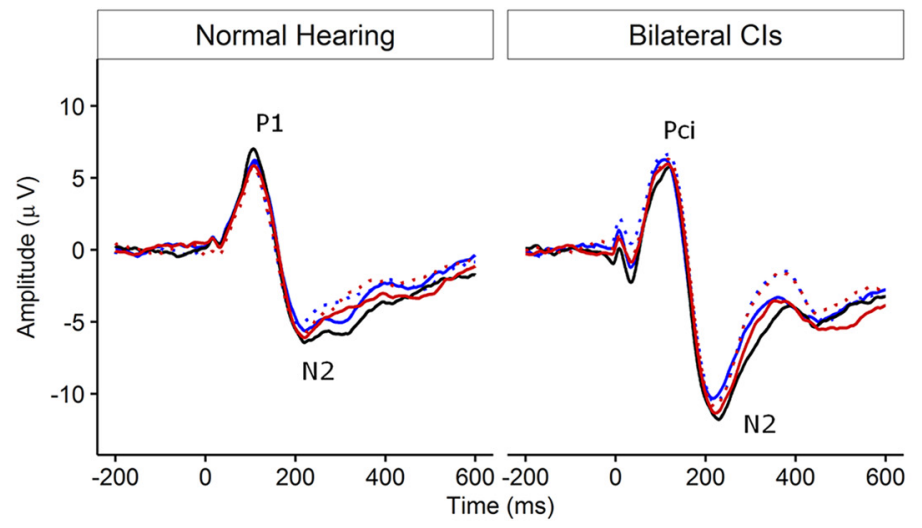

B
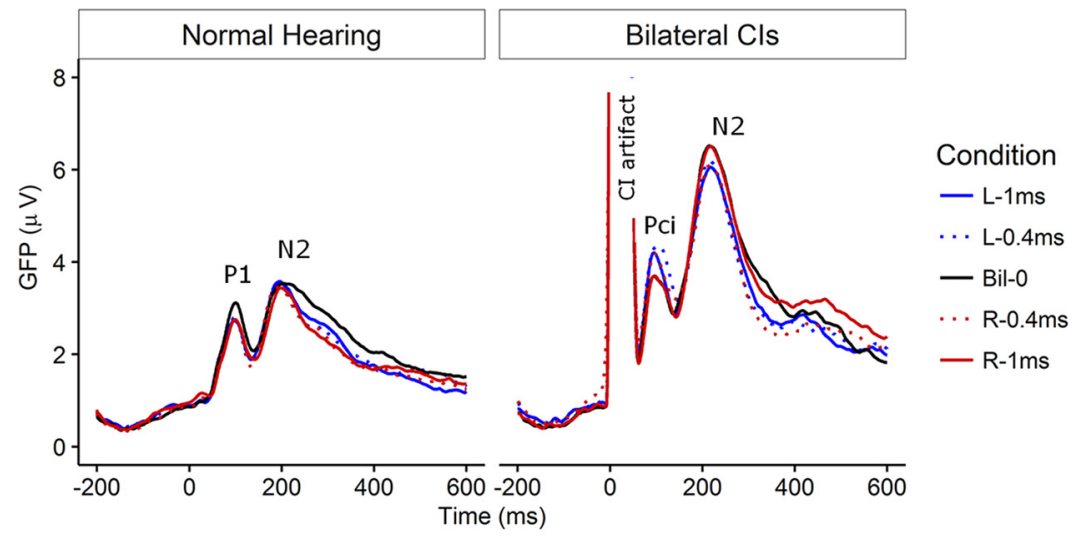

C
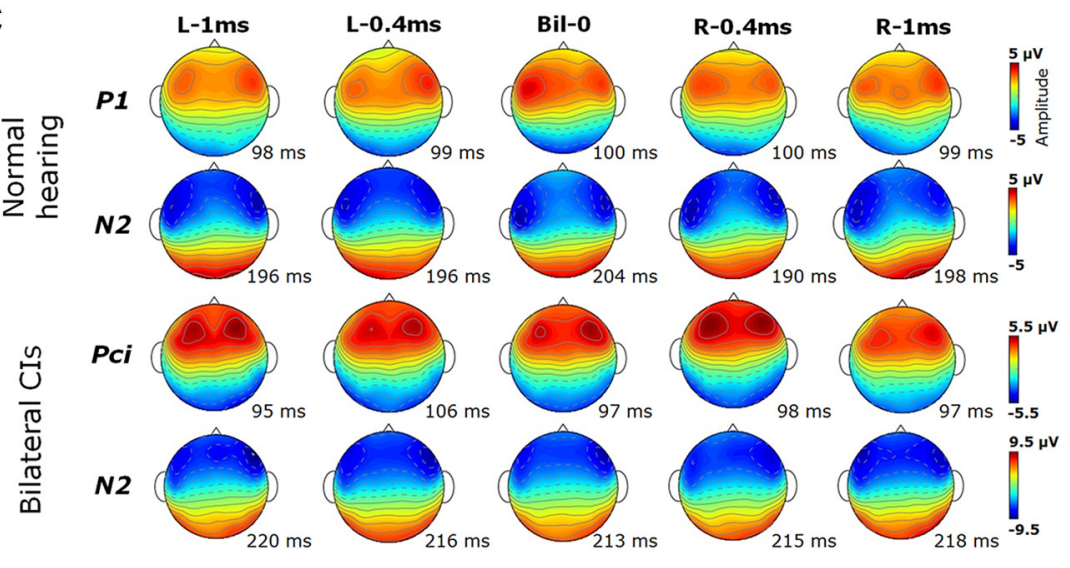

Figure 3. Similar response morphology in both groups confirms similar length of hearing experience. Grand mean waveforms at $\mathrm{Z}$ (ear lobe reference; $\boldsymbol{A}$ ) and GFP $(\boldsymbol{B})$ illustrate immature biphasic cortical response in both groups. L, left leading ITDs; $\mathrm{R}$, right leading ITDs; Bil-0, 0 ITD (simultaneous onsent of bilateral stimuli); 0.4 and $1 \mathrm{~ms}$, ITDs at onset used. 0 ms on the $x$-axis indicates stimulus onset. C, Topographical distribution of the average-reference surface EEG at peak GFP latencies indicated for each condition.

between the two groups was confirmed by a significant group $\times$ condition interaction $\left(F_{(2.84,85.20)}=4.27, p=0.008\right)$. As evident in Figure $5 C$, averaged across the two hemispheres, children with normal hearing had significantly weaker cortical activity for ITDs leading from the ipsilateral side. Post hoc pairwise comparisons confirmed that ipsilateral leading ITDs elicited significantly lower activity than the Bil-0 condition with no ITD (I-1 ms: $t_{(15)}=-3.45$, $p=0.018$; I-0.4 ms: $\left.t_{(15)}=-3.86, p=0.016\right)$ and the $0.4 \mathrm{~ms}$ contralateral leading condition (I-1 ms: $t_{(15)}=-2.65, p=0.048$, I-0.4 ms: $\left.t_{(15)}=-2.63, p=0.048\right)$. The difference between ipsilateral and the $1 \mathrm{~ms}$ contralateral leading ITD, which was significant before correction for multiple comparisons, approached significance after correction (I-1 ms: $t_{(15)}=-2.35, p=0.065$, I-0.4 ms: $\left.t_{(15)}=-2.14, p=0.079\right)$. Peak dipole moment did not vary with the length of ITD (0.4 vs $1 \mathrm{~ms})$ within ipsilateral $\left(t_{(15)}=0.46, p=0.73\right)$ and within contralateral leading conditions $\left(t_{(15)}=\right.$ $-0.34, p=0.74)$. In children with CIs, no differences were found between any of the five conditions $(p>0.05$; Fig. $5 C)$. One child with CI (CI9) had abnormally high dipole activity in the left hemisphere during Pci ( $>28 \mathrm{nAm}$ in all conditions). We did not exclude data from this child as an outlier because bilateral stimulation levels remained constant. Exclusion of data from this child did not change the analysis outcome. In summary, both groups of children demonstrated similar right dominance during binaural processing. Children with normal hearing demonstrated significantly lower activity to ITDs leading from the ipsilateral side as expected, whereas children with CIs lacked this differentiation.

Similar to P1/Pci (Fig. 5A,B), mean $\mathrm{N} 2$ peak dipole moment in Figure $5 D$ illustrates generally higher peak activity in the right hemisphere compared with the left; however, no ITD-sensitive changes were found for this response peak. The

between groups $\left(\mathrm{F}_{(1,30)}=0.55, p=0.47\right)$, although GFP peak amplitude was higher in children with CIs (Table 2). Normal-like right dominance during bilateral stimulation confirms protection of bilateral pathways achieved through simultaneous bilateral implantation in children with deafness.

Although normal-like dominance of the right auditory cortex in response to bilateral input was evident in children with CIs, ITD-dependent changes in cortical activity were limited. Mean peak dipole moment values in Figure $5 A$ illustrate lower activity for ITD conditions leading from the ipsilateral side (relative to Bil-0 and ITDs leading from the contralateral side) in normalhearing children, but not in children with bilateral CIs. The pattern appears similar for both hemispheres in normal-hearing children. The difference in the effect of ITD on cortical activity main effect of hemisphere approached significance $\left(F_{(1,30)}=\right.$ $3.60, p=0.067$ ) in the three-way ANOVA (hemisphere, condition, group). Pooled across both groups and five conditions (nonsignificant group $\times$ hemisphere interaction, $F_{(1,30)}=0.45$, $p=0.51$; nonsignificant group $\times$ condition $\times$ hemisphere interaction, $F_{(4,120)}=0.86, p=0.49$ ), activity in the right hemisphere $(10.82 \pm 5.19 \mathrm{nAm})$ tended to be higher than activity in the left hemisphere $(8.79 \pm 7.38 \mathrm{nAm})$. The main effect of condition was nonsignificant demonstrating limited ITD sensitivity $\left(F_{(4,120)}=\right.$ 2.00, $p=0.09$ ), and the overall dipole activity was similar between groups $\left(F_{(1,30)}=0.065, p=0.80\right)$, although peak GFP amplitudes were higher in children with CIs (Table 2). The same child (CI9) had high activity in the left hemisphere also during N2 ( $>26 \mathrm{nAm}$ in all conditions). Exclusion of data from this child 
Table 2. GFP peak amplitude and latencies ${ }^{a}$

\begin{tabular}{|c|c|c|c|c|c|c|}
\hline & Group & $\mathrm{L}-1 \mathrm{~ms}$ & $\mathrm{~L}-0.4 \mathrm{~ms}$ & Bil-0 & $\mathrm{R}-0.4 \mathrm{~ms}$ & $\mathrm{R}-1 \mathrm{~ms}$ \\
\hline \multicolumn{7}{|c|}{ Amplitude ( $\mu \mathrm{V}$ ) } \\
\hline \multirow[t]{2}{*}{$\mathrm{P} 1 / \mathrm{Pci}$} & Normal hearing & $2.90 \pm 0.26$ & $2.94 \pm 0.22$ & $3.31 \pm 0.21$ & $2.87 \pm 0.19$ & $2.94 \pm 0.21$ \\
\hline & Bilateral Cls & $4.29 \pm 0.39$ & $4.29 \pm 0.37$ & $4.07 \pm 0.28$ & $4.33 \pm 0.28$ & $3.92 \pm 0.25$ \\
\hline \multirow[t]{2}{*}{$\mathrm{N} 2$} & Normal hearing & $4.03 \pm 0.24$ & $3.99 \pm 0.36$ & $4.21 \pm 0.37$ & $3.98 \pm 0.36$ & $3.88 \pm 0.25$ \\
\hline & Bilateral Cls & $6.76 \pm 0.43$ & $6.71 \pm 0.54$ & $6.50 \pm 0.59$ & $6.54 \pm 0.52$ & $6.92 \pm 0.49$ \\
\hline \multicolumn{7}{|c|}{ Latency (ms) } \\
\hline \multirow[t]{2}{*}{$\mathrm{P} 1 / \mathrm{Pci}$} & Normal hearing & $98.00 \pm 3.02$ & $95.00 \pm 2.37$ & $96.50 \pm 3.37$ & $96.81 \pm 2.21$ & $99.19 \pm 2.40$ \\
\hline & Bilateral Cls & $99.63 \pm 3.31$ & $101.63 \pm 3.01$ & $100.13 \pm 3.68$ & $99.00 \pm 3.25$ & $102.44 \pm 4.12$ \\
\hline \multirow[t]{2}{*}{ N2 } & Normal hearing & $233.19 \pm 13.92$ & $219.75 \pm 10.87$ & $226.88 \pm 12.81$ & $233.69 \pm 15.67$ & $216.06 \pm 9.32$ \\
\hline & Bilateral Cls & $216.44 \pm 6.28$ & $222.19 \pm 8.88$ & $212.25 \pm 6.31$ & $219.13 \pm 5.76$ & $217.00 \pm 4.90$ \\
\hline
\end{tabular}

${ }^{a}$ Data are mean \pm SE. Children with Cls had significantly higher GFP amplitude for Pci and N2 peaks compared with children with normal hearing $(p<0.001)$. Peak latencies did not differ by group ( $\left.p>0.05\right)$. R, right leading conditions; $\mathrm{L}$, left leading conditions; Bil-0, simultaneous onset of bilateral stimuli; 0.4 and $1 \mathrm{~ms}$, ITDs at stimulus onset.

\section{L-1ms}
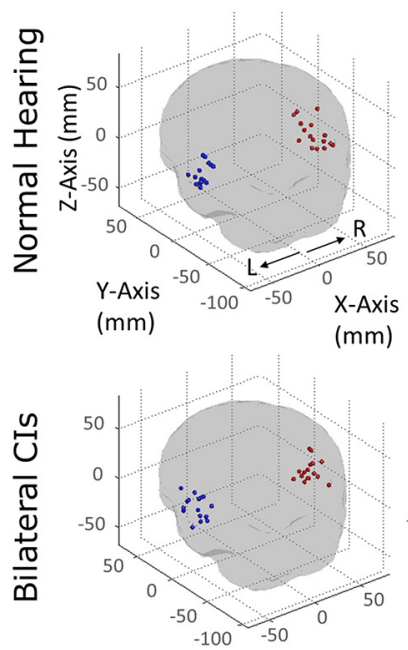

L-0.4ms
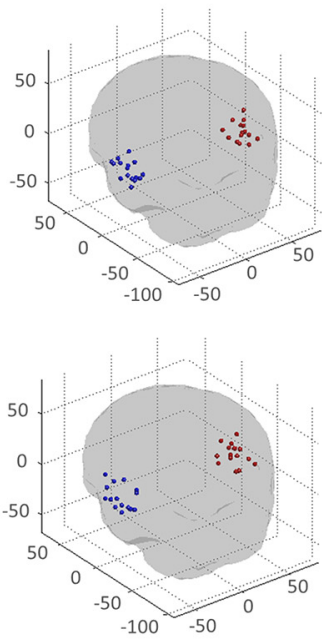

Bil-0
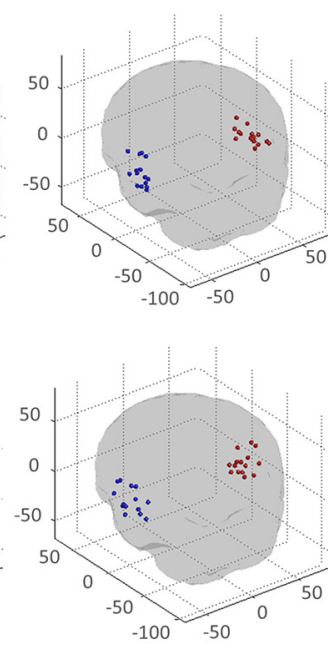

$\mathrm{R}-0.4 \mathrm{~ms}$
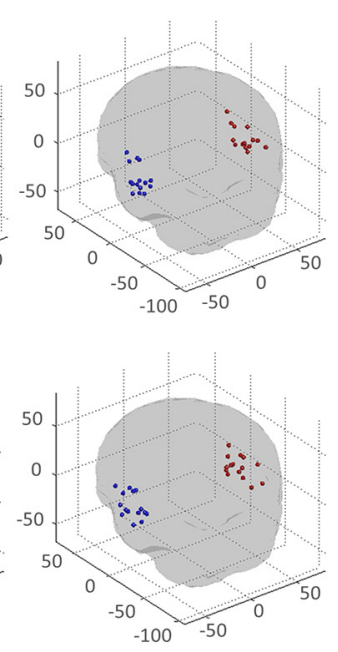

R-1ms
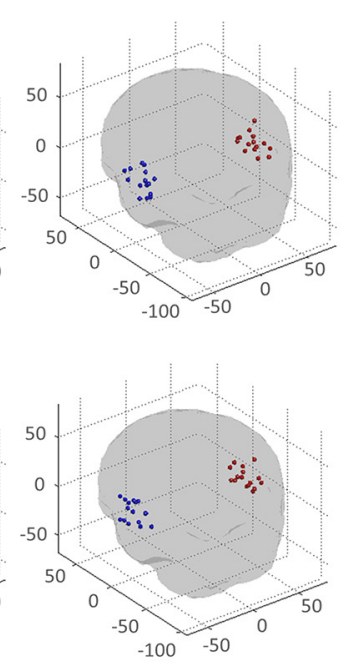

- Peak dipole in right auditory cortex (R)

- Peak dipole in left auditory cortex (L)

Figure 4. Peak dipoles (illustrated for P1/Pci only) were identified in similar locations across conditions in both groups of children.

rendered the main effect of hemisphere significant $\left(F_{(1,29)}=\right.$ $11.31, p=0.002)$. On average, right hemisphere activity $(10.59 \pm$ $5.11 \mathrm{nAm})$ was higher than left hemisphere activity (7.86 \pm 5.17 $\mathrm{nAm})$. No other main or interaction effects were found. In summary, cortical activity underlying N2, like the P1/Pci, had a right hemispheric bias in both groups.

Latency (P1/Pci) of peak dipole varied by group but not by condition (Table 3 ). A significant main effect of group on $\mathrm{P} 1 / \mathrm{Pci}$ latency $\left(F_{(1,28)}=4.20, p=0.049\right)$ was found in the three-way ANOVA (hemisphere, condition, group). Averaged across ITD conditions and hemispheres, Pci peak dipole latency in children with bilateral CIs $(95.99 \pm 17.39 \mathrm{~ms})$ was significantly shorter than children with normal hearing $(103.81 \pm 10.77 \mathrm{~ms})$ despite the lack of latency differences in the GFP (Table 2). No other main or interaction effects of condition were significant. No significant main or interaction effects were found for N2 peak dipole latency in the three-way ANOVA (hemisphere, condition, group). Peak dipole latencies are provided in Table 3.

\section{Children with bilateral CIs do not show expected changes in cortical lateralization with ITD}

Cortical lateralization was computed only for P1/Pci given that no ITD-sensitive changes were found for N2 (Fig. 5D). A main effect of condition (Bil-0, R/L-0.4, R/L-1 ms) was found on the cortical lateralization measure $\left(F_{(4,120)}=2.49, p=0.047\right)$; however, none of the conditions differed significantly in post hoc analyses after false discovery rate correction. This may be due to the relatively small changes in far-field/surface-based lateralization measures from a population of neurons (Werner-Reiss and Groh, 2008) and/or individual variability. Further analyses probed two questions about ITD-sensitive changes in cortical lateralization: (1) Does cortical lateralization vary by hemifield and ITDs within the same hemifield (Bil-0 condition excluded)? (2) Does cortical lateralization reflect a change between the presence and absence of an ITD (ITD conditions vs Bil-0)?

As plotted in Figure 6A, lateralization indices varied between hemifields more than within each hemifield. In normal-hearing children, cortical lateralization of left leading stimuli was more right hemisphere weighted relative to right leading stimuli, changing from a right lateralized pattern to bilaterally distributed activity. This is consistent with both the dominance of activity in the right auditory cortex and the reduction of dipole moment ipsilateral to the side of the leading ITD (Fig. 5). Relatively, smaller differences were evident between 0.4 and $1 \mathrm{~ms}$ ITDs leading from the same hemifield. In comparison, children with CIs showed similar lateralization for left and right leading ITDs. 

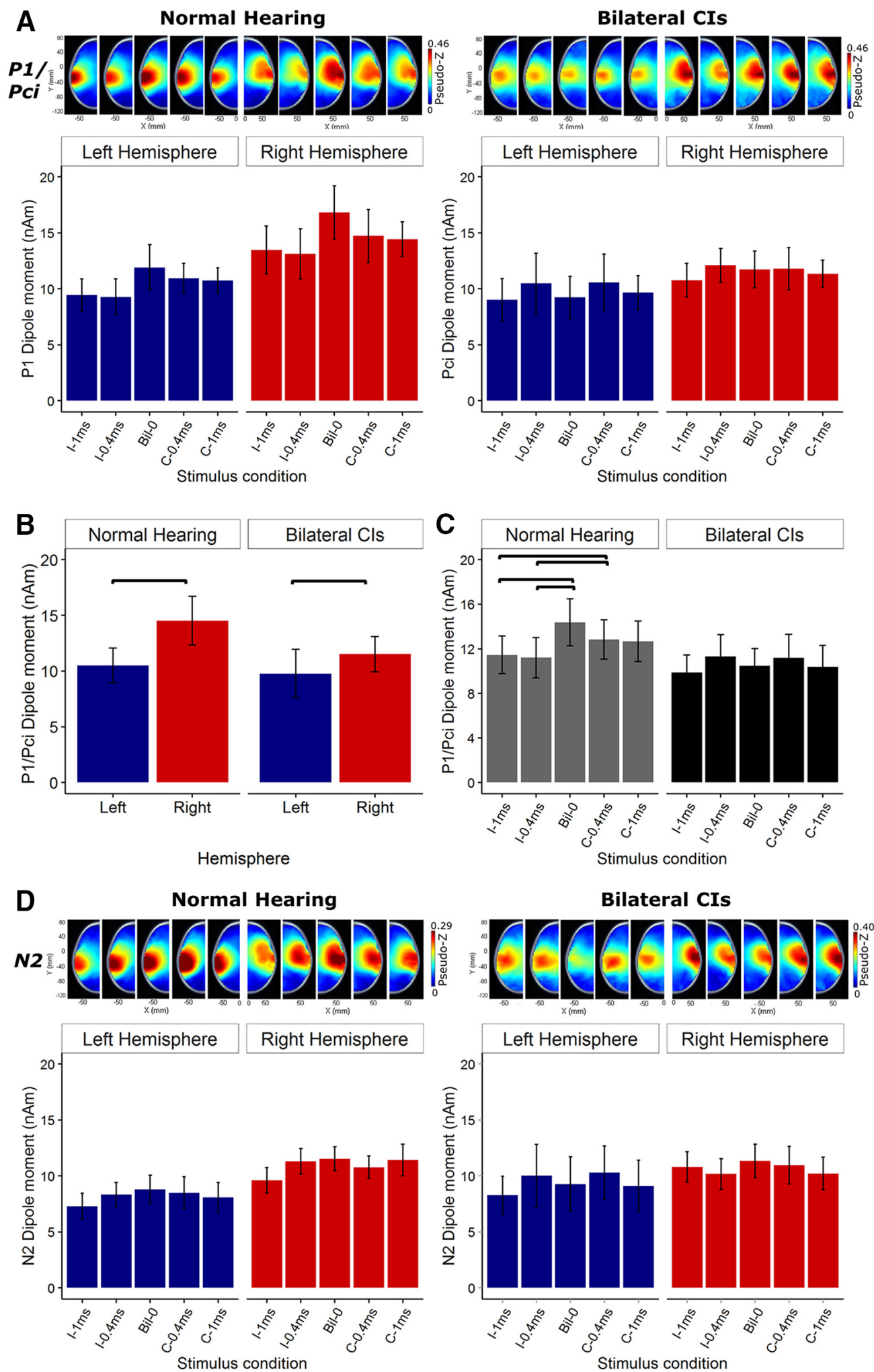

Figure 5. Both children with normal hearing and bilateral Cls demonstrated dominance of the right auditory cortex during binaural listening; however, cortical activity in children using Cls was less sensitive to changes in ITD. A, Average pseudo-Z maps (top row), mean peak dipole moment (bottom row) across ITDs for P1 in normal-hearing children and Pci in children with bilateral Cls. I, ipsilateral leading ITD conditions; $C$, contralateral leading ITD conditions. The pseudo-Z maps from each condition were split by hemisphere to correspond to the conditions in the bottom graph. Axes are in MNI coordinates (millimeters). $\boldsymbol{B}$, Increased peak dipole moment in the right relative to left hemisphere, averaged across all ITD conditions, is evident in both groups. $\boldsymbol{C}$, Averaged across hemispheres, children with normal hearing exhibited reduced activity for ITDs leading from the ipsilateral side during P1, whereas this was unclear in children with bilateral Cls. Horizontal bracketed lines indicate significant differences between conditions. $D$, Average pseudo-Z maps (top row), mean peak dipole moment (bottom row) across ITDs for N2 in normal-hearing children and children with bilateral Cls. A tendency for increased activity in the right rather than left auditory cortex ( $p=0.067)$ was evident in both groups, but N2 peak activity did not vary by condition. Error bars indicate SE. 
Table 3. P1/Pci and N2 peak dipole latencies across conditions ${ }^{a}$

\begin{tabular}{llllcrrr}
\hline & Group & Hemisphere & I-1 ms & I-0.4 ms & \multicolumn{1}{l}{ Bil-0 } & C-0.4 ms & C-1 ms \\
\hline P1/Pci & Normal hearing & Left & $104.50 \pm 3.50$ & $103.73 \pm 2.05$ & $107.69 \pm 2.17$ & $103.75 \pm 2.75$ \\
& & Right & $104.75 \pm 2.66$ & $102.69 \pm 2.50$ & $101.69 \pm 2.32$ & $100.69 \pm 2.95$ & $107.12 \pm 2.22$ \\
& Bilateral Cls & Left & $96.06 \pm 5.60$ & $95.80 \pm 4.96$ & $98.40 \pm 4.22$ & $95.88 \pm 4.27$ & $97.88 \pm 4.53$ \\
& & Right & $94.56 \pm 3.94$ & $92.73 \pm 3.37$ & $93.12 \pm 3.60$ & $100.88 \pm 6.04$ & $94.50 \pm 3.47$ \\
N2 & Normal hearing & Left & $207.87 \pm 4.51$ & $201.88 \pm 8.20$ & $207.81 \pm 6.55$ & $203.81 \pm 10.93$ & $216.56 \pm 10.82$ \\
& & Right & $210.56 \pm 9.54$ & $207.88 \pm 10.56$ & $210.31 \pm 10.60$ & $206.88 \pm 9.79$ & $210.19 \pm 11.95$ \\
& Bilateral Cls & Left & $208.44 \pm 4.36$ & $200.00 \pm 4.97$ & $206.73 \pm 7.44$ & $205.71 \pm 4.43$ & $212.62 \pm 5.02$ \\
& & Right & $203.69 \pm 6.56$ & $206.12 \pm 7.03$ & $197.62 \pm 7.89$ & $203.75 \pm 5.80$ & $205.31 \pm 7.68$ \\
\hline
\end{tabular}

${ }^{a}$ Data are mean \pm SE in milliseconds. Children with bilateral Cls had significantly shorter Pci latencies compared with P1 in normal-hearing children ( $\left.p=0.049\right)$. No significant group or condition effects were found for N2 latencies. I, ipsilateral leading conditions; C, contralateral leading conditions; Bil-0, simultaneous onset of bilateral stimuli.

Sensitivity of the lateralization measure to between-hemifield changes in children with normal hearing and the lack thereof in children with CIs was confirmed by a significant two-way interaction (group $\times$ hemifield, $F_{(1,30)}=4.75, p=0.037$ ) in the threeway ANOVA (hemifield [left/right], ITD [0.4 ms, $1 \mathrm{~ms}]$, group). In children with normal hearing, left leading ITDs (19.96 \pm $20.50 \%)$ were significantly more right lateralized than right leading ITDs $\left(7.04 \pm 21.78 \%, t_{(15)}=4.27, p<0.001\right)$. This change was nonsignificant in children with bilateral CIs (left leading ITDs: $13.68 \pm 25.12 \%$; right leading ITDs: $12.17 \pm 26.41 \%$; $t_{(15)}=$ $0.35, p=0.73)$. The limited within-hemifield sensitivity of lateralization index was confirmed by nonsignificant main $\left(F_{(1,30)}=\right.$ $0.02, p=0.89)$ and interaction effects of ITD (ITD $\times$ group, $F_{(1,30)}=0.04, p=0.84$; ITD $\times$ hemifield, $F_{(1,30)}=0.05, p=$ $0.83)$. The lack of differences in cortical lateralization between the two large ITDs leading from the same hemifield parallels similar behavioral lateralization performance for these same stimuli in children with normal hearing (Gordon et al., 2014). The smaller within-hemifield than between-hemifield differences are consistent with broadly tuned opponent channels with shallow rateazimuth slopes for location changes away from the midline (Stecker et al., 2005).

To evaluate if lateralization could indicate detection of ITD from the Bil-0 condition, (1) a two-way ANOVA (condition [L-/ R-lead/Bil-0], group) was performed on lateralization indices averaged over 0.4 and $1 \mathrm{~ms}$ ITDs in each hemifield given that lateralization did not vary by within-hemifield ITDs (Fig. 6A); and (2) lateralization slope (computed as the linear rate of change in lateralization index between left leading, Bil-0 and right leading ITD conditions) was compared between the groups using an independent $t$ test. We speculated that slope measures may be more sensitive because the detection of ITD would likely depend on the change from Bil-0, rather than the absolute lateralization index, and that the absolute lateralization index at Bil-0 may vary across individuals.

Post hoc analyses following the significant main effect of condition $\left(F_{(2,60)}=4.02, p=0.022\right)$ revealed greater right lateralized activity for left $(16.82 \pm 22.78 \%)$ than right leading stimuli $\left(9.60 \pm 23.96 \% ; t_{(31)}=2.60, p=0.042\right.$; Fig. $\left.6 B\right)$, as expected from Figure $6 \mathrm{~A}$. The degree of right lateralized activity was similar for the Bil-0 condition $(16.43 \pm 24.98 \%)$ and left leading stimuli $\left(16.81 \pm 22.78 \%, t_{(31)}=-0.13, p=0.89\right)$. The difference between Bil-0 (16.43 $\pm 24.98 \%)$ and right leading stimuli (9.60 \pm $23.96 \%)$ approached significance $\left(t_{(31)}=2.23, p=0.05\right)$. The main effect of group $\left(F_{(1,30)}=0.03, p=0.87\right)$ and interaction between group and condition $\left(F_{(2,60)}=2.08, p=0.13\right)$ were nonsignificant. Although group differences with absolute lateralization indices were nonsignificant, the slopes (shown in Fig. 6C) were significantly lower in children with bilateral CIs $(-0.75 \pm$ 8.56) relative to children with normal hearing $(-6.46 \pm 6.05$; $\left.t_{(27.0)}=-2.18, p=0.038\right)$. The shallower slope in children with CIs is consistent with impaired change in behavioral lateralization with ITDs (Gordon et al., 2014, their Figs. 2, 3). This suggests that the overall slope, as opposed to the absolute lateralization indices, more likely reflects poorer-than-normal behavioral ITD detection in children with bilateral CIs.

In summary, cortical lateralization measures corroborate findings of right hemispheric dominance to bilateral click/pulse trains with decreasing ipsilateral activity to ITDs leading from the same side (Fig. 5). The shift in right lateralized activity for left leading ITDs to more bilateral activity for right leading ITDs was not found in children with bilateral CIs (Fig. 6A). Moreover, the change in cortical lateralization was reduced in children with bilateral CIs compared with normal-hearing children (Fig. 6C). This parallels poorer behavioral detection of ITDs (Gordon et al., 2014). The significant group effects shown by slope of lateralization and not by absolute lateralization suggest a limitation of using absolute lateralization measures across ITD conditions and/or individual variability in ITD impairment among children with bilateral CIs. Either issue would reduce the detectable differences in absolute lateralization between groups.

\section{Children with bilateral CIs do not show expected hemispheric differences for ITD processing}

Similar to cortical lateralization scores, right and left leading ITD weighting was computed only for P1/Pci given that no ITDsensitive changes were found for $\mathrm{N} 2$ (Fig. 5D). Individual and mean weighting indices in Figure $7 B$ indicate a difference in preference for right and left leading stimuli between the two hemispheres in normal-hearing children but not in children with CIs. This was confirmed by a significant three-way interaction (group, hemisphere, hemifield; $\left.F_{(1,30)}=4.89, p=0.035\right)$ in the four-way ANOVA (group, hemisphere, hemifield, ITD). Collapsed across ITDs (no significant main effects or interactions), in normalhearing children (Fig. $7 B$ ), the left hemisphere showed a significantly higher weighting for right leading stimuli $(54.88 \pm 4.54 \%)$ relative to left leading stimuli $\left(45.12 \pm 4.54 \%\right.$; $t_{(15)}=4.30, p=$ 0.001 , whereas the right hemisphere showed no significant difference (left-lead weighting: $51.90 \pm 5.18 \%$, right-lead weighting: $\left.48.09 \pm 5.19 \% ; t_{(15)}=-1.47, p=0.16\right)$. In children with bilateral CIs, no hemispheric differences were found (right hemisphere: $t_{(15)}=0.47, p=0.64$, left hemisphere: $t_{(15)}=1.11, p=$ $0.58)$. The lack of a significant effect of ITD ( $0.4 \mathrm{vs} 1 \mathrm{~ms})$ is consistent with the similarities in peak dipole moment (Fig. $5 \mathrm{C}$ ) and cortical lateralization index (Fig. 6A) for these stimuli.

\section{Children with CIs show deficits in nonauditory areas when listening bilaterally}

Between-group comparisons indicated lower than normal activity in children with CIs in nonauditory areas. The lack of condition-specific differences in auditory areas likely reflects the 

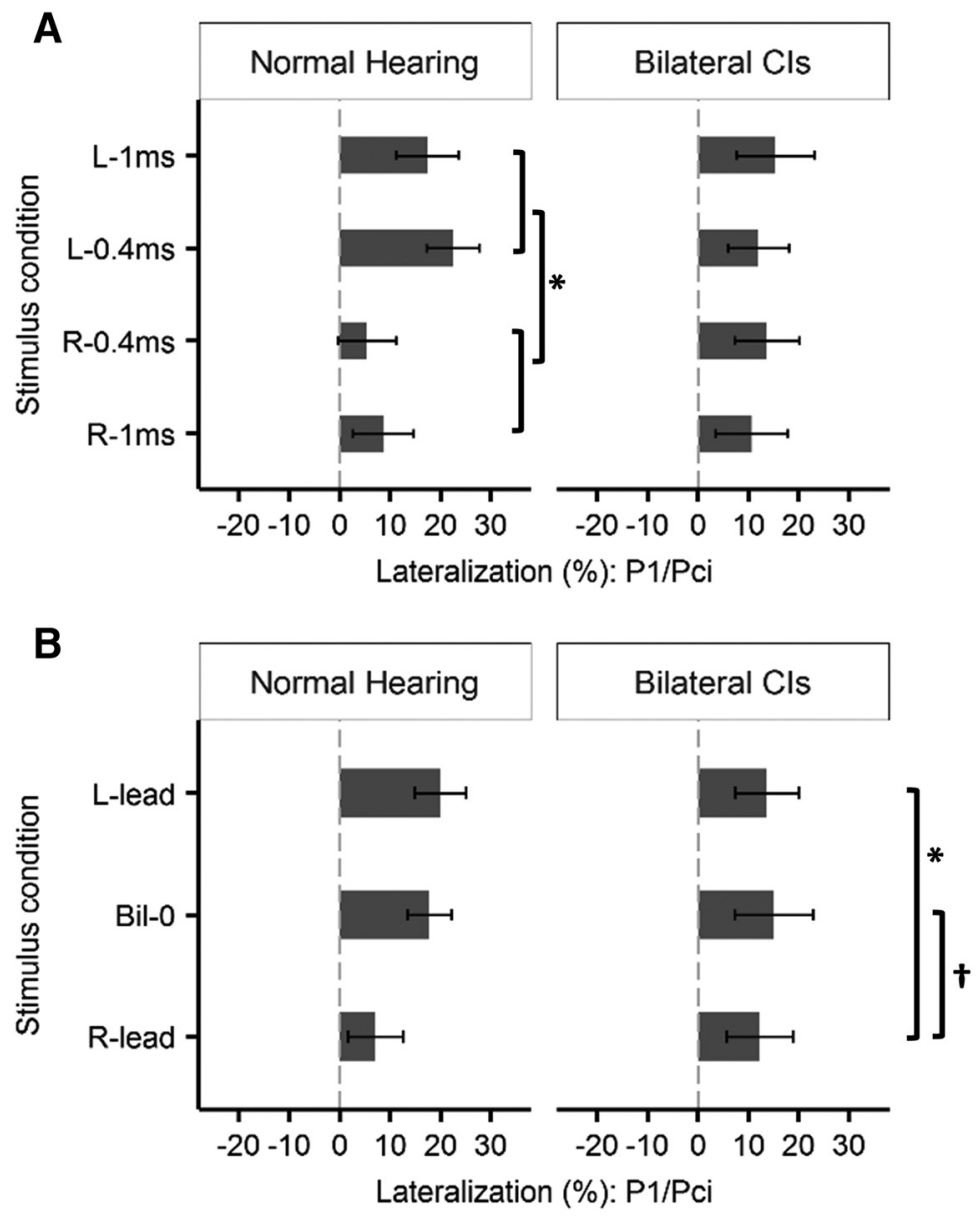

C Normal Hearing $\Delta$ Bilateral Cls

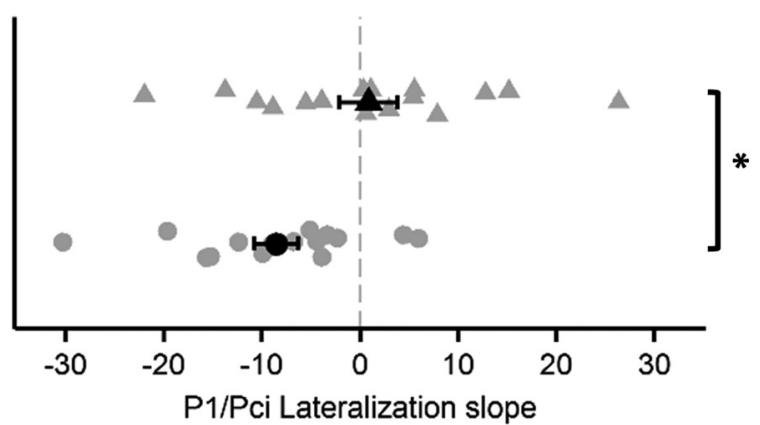

Figure 6. No significant ITD-dependent changes in cortical lateralization were evident in children with bilateral Cls. A, Cortical lateralization of $\mathrm{P} 1$ activity varied significantly for ITDs leading from opposite hemifields but not from within the same hemifield in children with normal hearing. Cortical lateralization did not vary between hemifields for children with bilateral Cls. ${ }^{*} p<0.05$. $\boldsymbol{B}$, Cortical lateralization of $\mathrm{P} 1$ activity was more right-weighted in left leading (L-lead) and Bil-0 conditions relative to right leading (R-lead) conditions. Lateralization indices in the 0.4 and $1 \mathrm{~ms}$ ITD conditions were averaged to representL-lead and R-lead conditions. Error bars indicate SE. Significant differences in $\boldsymbol{B}$ represent change in lateralization indices collapsed across both groups. ${ }^{\dagger} p=0.05$. C, Cortical lateralization slope (computed as the linear rate of change in lateralization between left leading, Bil-0 0 and rightleading ITD conditions) was significantly lower in children with bilateral Cls compared with children with normal hearing.

reduced power of the between-group comparisons and slightly variable locations of peak dipoles within the defined auditory cortex chosen for each condition (Fig. 4) in comparison to repeated-measures analyses of peak dipole moment (Fig. 5). Figure 8 illustrates that decreased activity in children with bilateral CIs occurs in fairly consistent cortical locations across all conditions and both response peaks, suggesting that these deficits were not specific to conditions with an ITD. Regions of lower activity in children with CIs included the precuneus and cuneus, inferior and middle occipital lobe, inferior parietal lobe, fusiform gyrus, and posterior cingulate gyrus. The inferior and middle occipital gyrus, inferior parietal lobe, fusiform gyrus, cuneus, and precuneus were also identified with significantly reduced activity from normal in bilateral and unilateral conditions in a subset of children in the present cohort (Easwar et al., 2017). One focused region of higher activity in the CI group was evident in the right inferior frontal gyrus during $\mathrm{N} 2$ while processing the $1 \mathrm{~ms}$ right leading condition, but this included only one voxel and thus was not considered further. In summary, regions in the right hemisphere, associated with spatial hearing, showed deficits in activity in children using bilateral CIs.

\section{Discussion}

The present study evaluated cortical representation of ITDs in young normalhearing children and children with longterm experience using simultaneously implanted bilateral CIs. Our findings are: (1) dominant right cortical activity during bilateral stimulation in both groups, (2) reduction of P1 activity to ipsilaterally leading ITDs and hemispheric asymmetry for weighting contralateral leading ITDs in normal-hearing children, (3) limited cortical ITD sensitivity in children with CIs, and (4) lower than normal activity in nonauditory areas in CI users.

\section{Cortical representation of ITD in young normal-hearing children resembles mature patterns}

Dominant right cortical activity in young children with normal hearing (Fig. 4A-C) is consistent with findings in adults for spatially informative stimuli (Palomäki et al., 2002; Brunetti et al., 2005; Johnson and Hautus, 2010). Stronger activity for contralateral leading ITDs (Fig. 5C) also resembles patterns in adults (McEvoy et al., 1993; Palomäki et al., 2005; Johnson and Hautus, 2010) and concurs with the distribution of best ITDs in mammalian brainstem (Hancock et al., 2010, 2013) and cortex (Werner-Reiss and Groh, 2008; Tillein et al., 2010, 2016). Although contralaterally biased responses are dominant, prevalence of ipsilateral ITD preferring neurons and neurons with complex preference patterns (WernerReiss and Groh, 2008; Tillein et al., 2016), along with wide receptive areas of cortical neurons (Middlebrooks et al., 1994; Chadderton et al., 2009), reduce the cumulative contralaterality assessed by imaging (Werner-Reiss and Groh, 2008). Although right domi- 
A

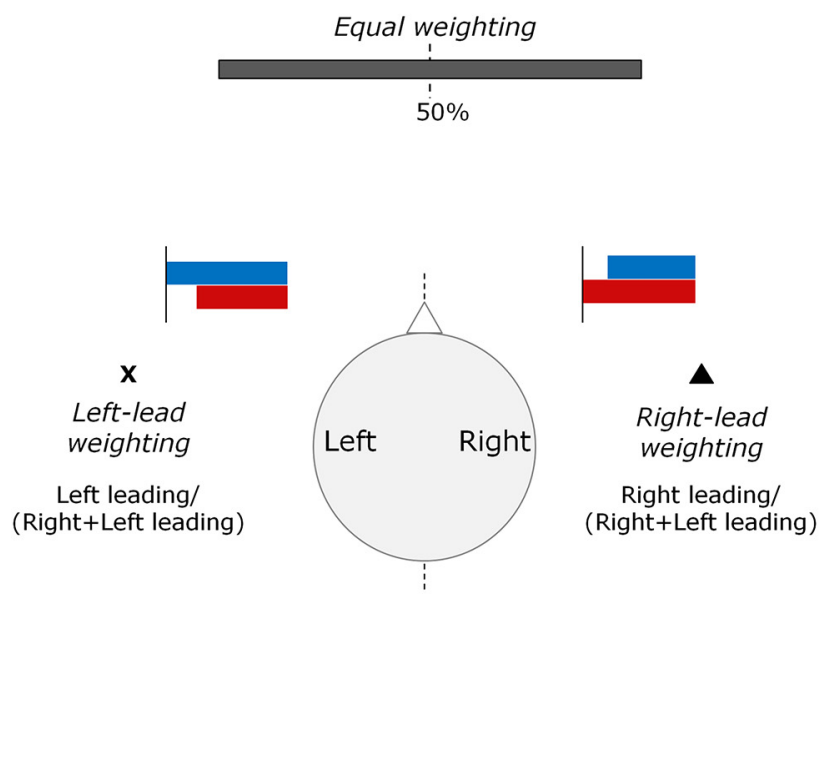

B

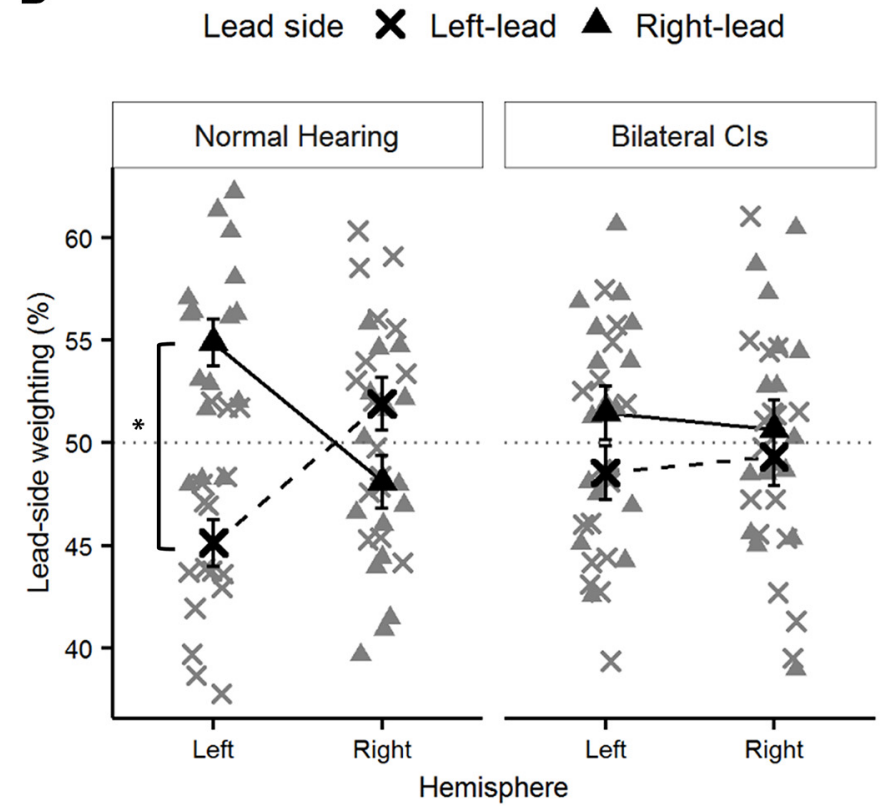

Figure 7. The left auditory cortex uniquely weighs leading ITDs in children with normal hearing. This specialized processing of ITDs is not found in children with Cls. A, Computation of normalized weighting (\%) for processing ITDs leading from right and left hemifields. Right-lead weighting (right leading/[right leading + left leading] $\times 100$ ) and left-lead weighting (left leading/[right leading + left leading] $\times 100$ ) (Briley et al., 2013) was computed using peak dipole moment for each hemisphere at the same ITD. $\boldsymbol{B}$, Group mean (black) and individual (gray) lead-side weighting for left and right hemispheres. *Significantly higher right-lead than left-lead weighting for the left hemisphere in normal-hearing children. The tendency for higher left-lead than right-lead weighting for the right hemisphere was nonsignificant in normal-hearing children. No such differences were found in children with bilateral Cls. Data represent weighting indices averaged between 0.4 and $1 \mathrm{~ms}$ ITDs leading from the same side. Error bars indicate SE.

nance was also evident during $\mathrm{N} 2$, the lack of ITD sensitivity is contradictory to one report in adults measured in an active task (Johnson et al., 2007). It is possible that insensitivity of N2 to ITDs reflects topdown processes that can alter spatial tuning (Lee and Middlebrooks, 2010).

Normal-hearing children also demonstrated a panoramic role of the right hemisphere in ITD processing in contrast to the stronger weighting of the left hemisphere for right leading ITDs (Fig. 7B). This may reflect differences in the balance of neuronal populations tuned to ipsilateral and contralateral leading ITDs in each hemisphere, and supports a 3-channel model consisting of a contralateral channel in each hemisphere and an additional ipsilateral channel in the right hemisphere (Krumbholz et al., 2005, 2007; Magezi and Krumbholz, 2010; Briley et al., 2013; McLaughlin et al., 2016; however, see Salminen et al., 2010). This hemispheric asymmetry is also supported by lesion studies in which right hemispheric lesions cause spatial deficits in both hemifields while left hemispheric lesions lead to deficits restricted to the right hemifield (Zatorre and Penhune, 2001; Spierer et al., 2009).

Cortical processing of ITDs in the normal-hearing children here is consistent with adult-like spatial hearing abilities in 4- to 5-year-olds (Litovsky, 1997; Van Deun et al., 2009). Early development of spatial processing is likely possible due to functional binaural circuits evident at birth. Although monaural response characteristics are immature, adult-like processing of binaural
L-1ms L-0.4ms
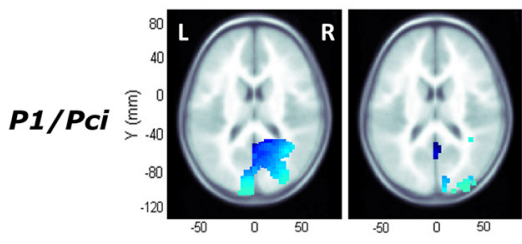

Bil-0

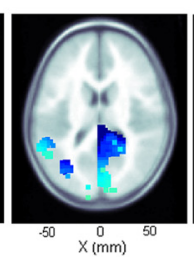

R-0.4ms
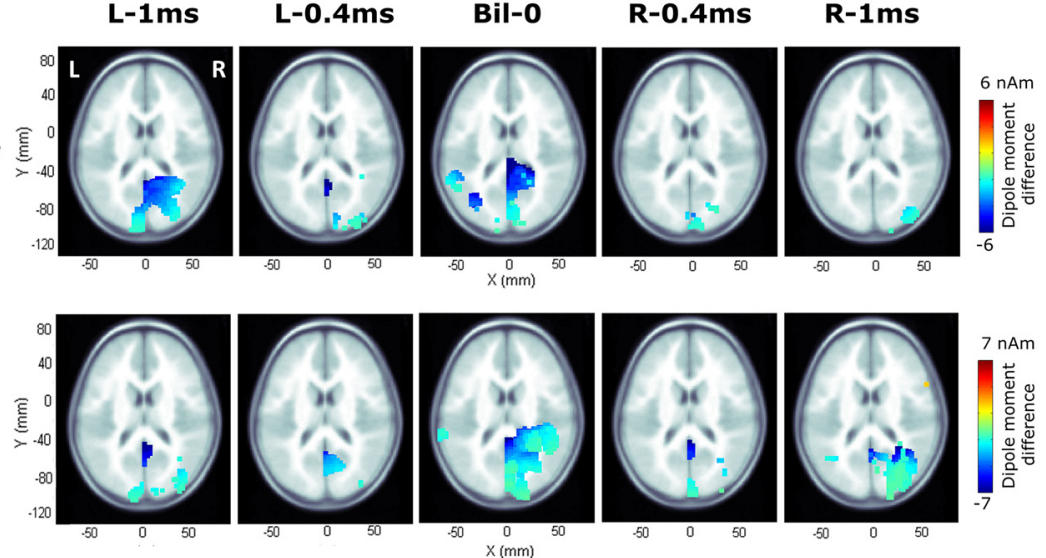

Figure 8. Between-group differences in cortical activity (peak dipole moment) in all voxels evaluated using unpaired two-sided permutation tests (Bonferroni-corrected; adjusted $p$ value $=0.05 / 62$ recording electrodes $=0.0008$ ). Hotter colors represent higher activity in children with Cls. Cooler colors represent higher activity in children with normal hearing. Children with Cls exhibited lower cortical activity most commonly in right cerebral regions, including cuneus, precuneus, inferior and middle occipital lobe, inferior parietal lobe, and postcingulate cortex during P1/Pci and N2.

cues is evident in kitten IC (Blatchley and Brugge, 1990) and auditory cortex (Brugge et al., 1988), likely mediated through matched monaural afferent pathways (Blatchley and Brugge, 1990). Adult-like brainstem interactions for binaural processing are also evident in newborn infants (McPherson et al., 1989; Cone-Wesson et al., 1997). Although delayed and harder to detect, binaural interactions are evident even for ITDs up to $1 \mathrm{~ms}$ (Furst et al., 2004). Infant cortical activity is sensitive to spatial cues but lack adult-like contralaterality for lateralized stimuli (Németh et al., 2015). Evidence of adult-like patterns in the present study demonstrates developmental advances molded by hearing experience with age. 


\section{Development of cortical ITD processing is impaired in children who are deaf and have limited access to reliable binaural timing cues}

Normal-like right cortical dominance during binaural listening in children with CIs (Fig. 5B) indicates that bilateral auditory pathways have been protected from unilaterally driven reorganization (Jiwani et al., 2016). These data reinforce the recommendation for bilateral implantation in children without delay (Gordon et al., 2013, 2015). We cannot speculate on the effects of late but bilateral simultaneous implantation on right hemispheric dominance. However, the lack of contralaterally biased ITD processing (Fig. $5 C$ ), reduced change in cortical lateralization with ITD (Fig. 6A,C), and limited asymmetry in hemispheric preference for leading ITDs (Fig. $7 B$ ) in current study CI cohort suggest that early symmetrical input is essential but insufficient for normal development of ITD coding. This is true despite controlling for length of hearing experience. Similar cohorts $\log \sim 9.5 \mathrm{~h}$ of average device use/d (Easwar et al., 2016), making inconsistent use an unlikely contributor. It is also unlikely that stimulus disparities contributed to group differences because normal-hearing children detect ITDs even with limited temporal fine structure cues, simulating CI stimulation (Ehlers et al., 2016). ITD processing deficits therefore reflect early-onset deafness and/or the nature of hearing experience.

Deaf animals show changes in auditory pathways involved in ITD processing, including the following: reduced cochlear nucleus volume (Hardie and Shepherd, 1999); reduced branching and density in endbulbs of held (Ryugo et al., 1997); lower temporal firing precision in the medial nucleus of trapezoid body (Leao et al., 2004); lower excitatory and inhibitory medial superior olive input (Kandler and Gillespie, 2005; Tirko and Ryugo, 2012); fewer ITD-sensitive IC neurons with limited contralateral bias (Hancock et al., 2010, 2013); and high prevalence of nonresponsive cortical sites with reduced firing rates (Tillein et al., 2010, 2016). Although bilateral CI stimulation can revert function in binaural nuclei (Tirko and Ryugo, 2012), the extent of recovery in humans is unknown. Earlier (relative to late/postlingual deafness) and longer deprivation worsens ITD sensitivity (Litovsky et al., 2010; Hancock et al., 2013), suggesting that early (pre-CI) years of deprivation could contribute to ITD processing deficits in behavioral (Gordon et al., 2014) and cortical measures in children with CIs.

Refinement of binaural networks subcortically is experienceand use-dependent. Guinea pigs reared in omnidirectional noise lack collicular spatial maps (Withington-Wray et al., 1990), and similarly raised gerbils fail selective pruning of inhibitory inputs to medial superior olive (Kapfer et al., 2002). Although simultaneous provision of two CIs provides the best clinical option for developing spatial hearing through symmetrical sensitivity to both hemifields, reliable ITDs may be unavailable with two independently functioning CIs. Each CI convolves the input envelope with a constant-rate pulse train; their independent clocks therefore introduce unintended ITDs unrelated to the fine structure (van Hoesel, 2004). This compromises consistency of ITD cues for reliable use and increases reliance on level cues for spatial hearing in CI users (e.g., Seeber and Fastl, 2008).

Electrical pulses may also impede normal development of ITD processing by evoking higher than acoustically driven neural synchrony (Hartmann et al., 1984), leading to saturation in binaural neurons and, consequently, poorer ITD sensitivity (Colburn et al., 2009; Laback et al., 2015). Lack of frequency-specific cochlear delay may also affect brainstem ITD coding (Colburn et al., 2009). Children with bilateral CIs do not show expected decre- ases in ipsilateral auditory cortex activity during unilateral stimulation (Easwar et al., 2017), which is consistent with the compressed differences for lateralized stimuli found here. In summary, ITD processing deficits may be due to the effects of deafness, current CI signal processing, and/or nature of electric hearing. The relative contributions of early-onset deafness and electric hearing could be investigated in future studies by comparing ITD processing in early- and late-onset deafness in CI users with matched CI experience.

In light of impaired cortical ITD processing in children using CIs, their improved ITD perception with long-term use (Gordon et al., 2014) could: (1) reflect reliance on alternate consistent cues similar to increased reliance on undistorted monaural spectral cues after unilateral ear plugging in ferrets (King et al., 2000); (2) indicate partial reliance on cortical processing for locating sounds in the correct target hemifield as in cats with bilateral cortical deactivation (Malhotra and Lomber, 2007); and (3) suggest subcortical mechanisms supporting localization as in hemispherectomized patients (Zatorre et al., 1995). Although one or more of these speculations may underlie compensatory mechanisms, significant abnormalities remain (Gordon et al., 2014).

\section{Deficits in binaural processing persist in nonauditory areas in children with CIs}

Children with CIs had lower than normal cortical activity mostly in right parieto-occipital regions across all bilateral conditions but similar activity in auditory/temporal areas (Fig. 8), indicating smaller abnormalities in auditory areas in children with CIs. Lower parieto-occipital activity may indicate spatial coding deficits (inferior parietal lobe: Griffiths et al., 1998; Weeks et al., 1999; Brunetti et al., 2005 and extrastriate visual cortex: Poirier et al., 2005; Collignon et al., 2008) and/or sensory integration (precuneus: Cavanna and Trimble, 2006). Because similar deficits were also evident during unilateral listening (Easwar et al., 2017), these results could reflect a generic processing deficit in children with deafness, or differences in default mode networks that entail the posterior cingulate cortex and precuneus (Utevsky et al., 2014). Alternatively, this may reflect visual attention deficits in children with CIs (Quittner et al., 2009) and consequently, differences in visual activity during data collection.

In conclusion, results indicate that (1) adult-like ITD processing is evident in young normal-hearing children with immature sound-evoked cortical activity and (2) early and simultaneous provision of two independently functioning CIs protects bilateral pathways from unilaterally driven reorganization but appears to be insufficient to fully reverse deafness-related deficits and promote normal ITD processing.

\section{Notes}

Supplemental material for this article is available at https://sickkids.box. $\mathrm{com} / \mathrm{s} / \mathrm{x} 8 \mathrm{q} 6 \mathrm{gh} 1 \mathrm{zt} 1 \mathrm{i} 6 \mathrm{~m} 2 \mathrm{z} 0 \mathrm{fahgel}$ xnqjfxm0v. This material has not been peer reviewed.

\section{References}

Ashmead DH, Davis DL, Whalen T, Odom RD (1991) Sound localization and sensitivity to interaural time differences in human infants. Child Dev 62:1211-1226. CrossRef Medline

Benjamini Y, Hochberg Y (1995) Controlling the false discovery rate: a practical and powerful approach to multiple testing. J R Stat Soc B 57: 289-300.

Blair RC, Karniski W (1993) An alternative method for significance testing of waveform difference potentials. Psychophysiology 30:518-524. CrossRef Medline

Blatchley BJ, Brugge JF (1990) Sensitivity to binaural intensity and phase 
difference cues in kitten inferior colliculus. J Neurophysiol 64:582-597. Medline

Briley PM, Kitterick PT, Summerfield AQ (2013) Evidence for opponent process analysis of sound source location in humans. J Assoc Res Otolaryngol 14:83-101. CrossRef Medline

Brugge JF, Reale RA, Wilson GF (1988) Sensitivity of auditory cortical neurons of kittens to monaural and binaural high frequency sound. Hear Res 34:127-140. CrossRef Medline

Brunetti M, Belardinelli P, Caulo M, Del Gratta C, Della Penna S, Ferretti A, Lucci G, Moretti A, Pizzella V, Tartaro A, Torquati K, Olivetti Belardinelli M, Romani GL (2005) Human brain activation during passive listening to sounds from different locations: an fMRI and MEG study. Hum Brain Mapp 26:251-261. CrossRef Medline

Cavanna AE, Trimble MR (2006) The precuneus: a review of its functional anatomy and behavioural correlates. Brain 129:564-583. CrossRef Medline

Chadderton P, Agapiou JP, McAlpine D, Margrie TW (2009) The synaptic representation of sound source location in auditory cortex. J Neurosci 29:14127-14135. CrossRef Medline

Chau W, McIntosh AR, Robinson SE, Schulz M, Pantev C (2004) Improving permutation test power for group analysis of spatially filtered MEG data. Neuroimage 23:983-996. CrossRef Medline

Colburn HS, Chung Y, Zhou Y, Brughera A (2009) Models of brainstem responses to bilateral electrical stimulation. J Assoc Res Otolaryngol 10: 91-110. CrossRef Medline

Collignon O, Davare M, De Volder AG, Poirier C, Olivier E, Veraart C (2008) Time-course of posterior parietal and occipital cortex contribution to sound localization. J Cogn Neurosci 20:1454-1463. CrossRef Medline

Cone-Wesson B, Ma E, Fowler CG (1997) Effect of stimulus level and frequency on ABR and MLR binaural interaction in human neonates. Hear Res 106:163-178. CrossRef Medline

Dalal SS, Sekihara K, Nagarajan SS (2006) Modified beamformers for coherent source region suppression. IEEE Trans Biomed Eng 53:1357-1363. CrossRef Medline

Ducommun CY, Murray MM, Thut G, Bellmann A, Viaud-Delmon I, Clarke S, Michel CM (2002) Segregated processing of auditory motion and auditory location: an ERP mapping study. Neuroimage 16:76-88. CrossRef Medline

Easwar V, Sanfilippo J, Papsin B, Gordon K (2016) Factors affecting daily cochlear implant use in children: datalogging evidence. J Am Acad Audiol 27:824-838. CrossRef Medline

Easwar V, Yamazaki H, Deighton M, Papsin B, Gordon K (2017) Simultaneous bilateral cochlear implants: Developmental advances do not yet achieve normal cortical processing. Brain Behav 00:e00638. CrossRef

Ehlers E, Kan A, Winn MB, Stoelb C, Litovsky RY (2016) Binaural hearing in children using Gaussian enveloped and transposed tones. J Acoust Soc Am 139:1724-1733. CrossRef Medline

Furst M, Bresloff I, Levine RA, Merlob PL, Attias JJ (2004) Interaural time coincidence detectors are present at birth: evidence from binaural interaction. Hear Res 187:63-72. CrossRef Medline

Gordon KA, Salloum C, Toor GS, van Hoesel R, Papsin BC (2012) Binaural interactions develop in the auditory brainstem of children who are deaf: effects of place and level of bilateral electrical stimulation. J Neurosci 32:4212-4223. CrossRef Medline

Gordon KA, Wong DD, Papsin BC (2013) Bilateral input protects the cortex from unilaterally-driven reorganization in children who are deaf. Brain 136:1609-1625. CrossRef Medline

Gordon KA, Deighton MR, Abbasalipour P, Papsin BC (2014) Perception of binaural cues develops in children who are deaf through bilateral cochlear implantation. PLoS One 9:e114841. CrossRef Medline

Gordon K, Henkin Y, Kral A (2015) Asymmetric hearing during development: the aural preference syndrome and treatment options. Pediatrics 136:141-153. CrossRef Medline

Gordon KA, Abbasalipour P, Papsin BC (2016) Balancing current levels in children with bilateral cochlear implants using electrophysiological and behavioural measures. Hear Res 335:193-206. CrossRef Medline

Griffiths TD, Rees G, Rees A, Green GG, Witton C, Rowe D, Büchel C, Turner R, Frackowiak RS (1998) Right parietal cortex is involved in the perception of sound movement in humans. Nat Neurosci 1:74-79. CrossRef Medline

Hancock KE, Noel V, Ryugo DK, Delgutte B (2010) Neural coding of interaural time differences with bilateral cochlear implants: effects of congenital deafness. J Neurosci 30:14068-14079. CrossRef Medline
Hancock KE, Chung Y, Delgutte B (2013) Congenital and prolonged adult-onset deafness cause distinct degradations in neural ITD coding with bilateral cochlear implants. J Assoc Res Otolaryngol 14:393-411. CrossRef Medline

Hardie NA, Shepherd RK (1999) Sensorineural hearing loss during development: morphological and physiological response of the cochlea and auditory brainstem. Hear Res 128:147-165. CrossRef Medline

Hartmann R, Topp G, Klinke R (1984) Discharge patterns of cat primary auditory fibers with electrical stimulation of the cochlea. Hear Res 13:4762. CrossRef Medline

Jiwani S, Papsin BC, Gordon KA (2016) Early unilateral cochlear implantation promotes mature cortical asymmetries in adolescents who are deaf. Hum Brain Mapp 37:135-152. CrossRef Medline

Johnson BW, Hautus MJ (2010) Processing of binaural spatial information in human auditory cortex: neuromagnetic responses to interaural timing and level differences. Neuropsychologia 48:2610-2619. CrossRef Medline

Johnson BW, Hautus MJ, Duff DJ, Clapp WC (2007) Sequential processing of interaural timing differences for sound source segregation and spatial localization: evidence from event-related cortical potentials. Psychophysiology 44:541-551. CrossRef Medline

Kandler K, Gillespie DC (2005) Developmental refinement of inhibitory sound-localization circuits. Trends Neurosci 28:290-296. CrossRef Medline

Kapfer C, Seidl AH, Schweizer H, Grothe B (2002) Experience-dependent refinement of inhibitory inputs to auditory coincidence-detector neurons. Nat Neurosci 5:247-253. CrossRef Medline

Khosla D, Ponton CW, Eggermont JJ, Kwong B, Don M, Vasama JP (2003) Differential ear effects of profound unilateral deafness on the adult human central auditory system. J Assoc Res Otolaryngol 4:235249. CrossRef Medline

King AJ, Parsons CH, Moore DR (2000) Plasticity in the neural coding of auditory space in the mammalian brain. Proc Natl Acad Sci U S A 97: 11821-11828. CrossRef Medline

Krumbholz K, Schönwiesner M, von Cramon DY, Rübsamen R, Shah NJ, Zilles K, Fink GR (2005) Representation of interaural temporal information from left and right auditory space in the human planum temporale and inferior parietal lobe. Cereb Cortex 15:317-324. CrossRef Medline

Krumbholz K, Hewson-Stoate N, Schönwiesner M (2007) Cortical response to auditory motion suggests an asymmetry in the reliance on interhemispheric connections between the left and right auditory cortices. J Neurophysiol 97:1649-1655. CrossRef Medline

Laback B, Egger K, Majdak P (2015) Perception and coding of interaural time differences with bilateral cochelar implants. Hear Res 322:138-150. CrossRef Medline

Leao RN, Berntson A, Forsythe ID, Walmsley B (2004) Reduced low-voltage activated $\mathrm{K}^{+}$conductances and enhanced central excitability in a congenitally deaf ( dn/dn) mouse. J Physiol 559:25-33. CrossRef Medline

Lee CC, Middlebrooks JC (2011) Auditory cortex spatial sensitivity sharpens during task performance. Nat Neurosci 14:108-114. CrossRef Medline

Litovsky RY (1997) Developmental changes in the precedence effect: estimates of minimum audible angle. J Acoust Soc Am 102:1739-1745. CrossRef Medline

Litovsky RY (2012) Development of binaural and spatial hearing. In: Human auditory development (Werner L, Ray RR, Popper AN, eds), p 286. London: Springer.

Litovsky RY, Jones GL, Agrawal S, van Hoesel R (2010) Effect of age at onset of deafness on binaural sensitivity in electric hearing in humans. J Acoust Soc Am 127:400-414. CrossRef Medline

Magezi DA, Krumbholz K (2010) Evidence for opponent-channel coding of interaural time differences in human auditory cortex. J Neurophysiol 104:1997-2007. CrossRef Medline

Malhotra S, Lomber SG (2007) Sound localization during homotopic and heterotopic bilateral cooling deactivation of primary and nonprimary auditory cortical areas in the cat. J Neurophysiol 97:26-43. CrossRef Medline

McEvoy L, Hari R, Imada T, Sams M (1993) Human auditory cortical mechanisms of sound lateralization: II. Interaural time differences at sound onset. Hear Res 67:98-109. CrossRef Medline

McLaughlin SA, Higgins NC, Stecker GC (2016) Tuning to binaural cues in 
human auditory cortex. J Assoc Res Otolaryngol 17:37-53. CrossRef Medline

McPherson DL, Tures C, Starr A (1989) Binaural interaction of the auditory brain-stem potentials and middle latency auditory evoked potentials in infants and adults. Electroencephalogr Clin Neurophysiol 74:124-130. CrossRef Medline

Middlebrooks JC, Clock AE, Xu L, Green DM (1994) A panoramic code for sound location by cortical neurons. Science 264:842-844. CrossRef Medline

Moore JK, Guan YL (2001) Cytoarchitectural and axonal maturation in human auditory cortex. J Assoc Res Otolaryngol 2:297-311. CrossRef Medline

Németh R, Háden GP, Török M, Winkler I (2015) Processing of horizontal sound localization cues in newborn infants. Ear Hear 36:550-556. CrossRef Medline

Palomäki KJ, Tiitinen H, Mäkinen V, May P, Alku P (2002) Cortical processing of speech sounds and their analogues in a spatial auditory environment. Cogn Brain Res 14:294-299. CrossRef Medline

Palomäki KJ, Tiitinen H, Mäkinen V, May PJ, Alku P (2005) Spatial processing in human auditory cortex: the effects of 3D, ITD, and ILD stimulation techniques. Cogn Brain Res 24:364-379. CrossRef Medline

Papsin BC, Gordon KA (2008) Bilateral cochlear implants should be the standard for children with bilateral sensorineural deafness. Curr Opin Otolaryngol Head Neck Surg 16:69-74. CrossRef Medline

Petersson KM, Nichols TE, Poline JB, Holmes AP (1999) Statistical limitations in functional neuroimaging: II. Signal detection and statistical inference. Philos Trans R Soc B Biol Sci 354:1261-1281. CrossRef Medline

Poirier C, Collignon O, DeVolder AG, Renier L, Vanlierde A, Tranduy D, Scheiber C (2005) Specific activation of the V5 brain area by auditory motion processing: an fMRI study. Cogn Brain Res 25:650-658. CrossRef Medline

Ponton CW, Eggermont JJ (2007) Electrophysiological measures of human auditory system maturation. In: Relationship with neuroanatomy and behaviour (Burkard RF, Don M, Eggermont JJ, eds), pp 385-402. New York: Lippincott Williams Wilkins.

Ponton CW, Eggermont JJ, Kwong B, Don M (2000) Maturation of human central auditory system activity: evidence from multi-channel evoked potentials. Clin Neurophysiol 111:220-236. CrossRef Medline

Ponton C, Eggermont JJ, Khosla D, Kwong B, Don M (2002) Maturation of human central auditory system activity: separating auditory evoked potentials by dipole source modeling. Clin Neurophysiol 113:407-420. CrossRef Medline

Quittner AL, Barker DH, Snell C, Cruz I, McDonald LG, Grimley ME, Botteri M, Marciel K (2009) Improvements in visual attention in deaf infants and toddlers after cochlear implantation. Audiol Med 5:242-249.

Ramsden JD, Gordon K, Aschendorff A, Borucki L, Bunne M, Burdo S, Garabedian N, Grolman W, Irving R, Lesinski-Schiedat A, Loundon N, Manrique M, Martin J, Raine C, Wouters J, Papsin BC (2012) European Bilateral Pediatric Cochlear Implant Forum consensus statement. Otol Neurotol 33:561-565. CrossRef Medline

Ryugo DK, Pongstaporn T, Huchton DM, Niparko JK (1997) Ultrastructural analysis of primary endings in deaf white cats: morphologic alterations in endbulbs of Held. J Comp Neurol 385:230-244. CrossRef Medline

Salloum CA, Valero J, Wong DD, Papsin BC, van Hoesel R, Gordon KA (2010) Lateralization of interimplant timing and level differences in children who use bilateral cochlear implants. Ear Hear 31:441-456. CrossRef Medline
Salminen NH, Tiitinen H, Miettinen I, Alku P, May PJ (2010) Asymmetrical representation of auditory space in human cortex. Brain Res 1306:93-99. CrossRef Medline

Seeber BU, Fastl H (2008) Localization cues with bilateral cochlear implants. J Acoust Soc Am 123:1030-1042. CrossRef Medline

Spierer L, Bellmann-Thiran A, Maeder P, Murray MM, Clarke S (2009) Hemispheric competence for auditory spatial representation. Brain 132: 1953-1966. CrossRef Medline

Stecker GC, Harrington IA, Middlebrooks JC (2005) Location coding by opponent neural populations in the auditory cortex. PLoS Biol 3:e78. CrossRef Medline

Steel MM, Papsin BC, Gordon KA (2015) Binaural fusion and listening effort in children who use bilateral cochlear implants: a psychoacoustic and pupillometric study. PLoS One 10:e0117611. CrossRef Medline

Tillein J, Hubka P, Syed E, Hartmann R, Engel AK, Kral A (2010) Cortical representation of interaural time difference in congenital deafness. Cereb Cortex 20:492-506. CrossRef Medline

Tillein J, Hubka P, Kral A (2016) Monaural congenital deafness affects aural dominance and degrades binaural processing. Cereb Cortex 26:17621777. CrossRef Medline

Tirko NN, Ryugo DK (2012) Synaptic plasticity in the medial superior olive of hearing, deaf, and cochlear-implanted cats. J Comp Neurol 520:22022217. CrossRef Medline

Utevsky AV, Smith DV, Huettel SA (2014) Precuneus is a functional core of the default-mode network. J Neurosci 34:932-940. CrossRef Medline

Van Deun L, van Wieringen A, Van den Bogaert T, Scherf F, Offeciers FE, Van de Heyning PH, Desloovere C, Dhooge IJ, Deggouj N, De Raeve L, Wouters J (2009) Sound localization, sound lateralization, and binaural masking level differences in young children with normal hearing. Ear Hear 30:178-190. CrossRef Medline

van Hoesel RJ (2004) Exploring the benefits of bilateral cochlear implants. Audiol Neurotol 9:234-246. CrossRef Medline

Weeks RA, Aziz-Sultan A, Bushara KO, Tian B, Wessinger CM, Dang N, Rauschecker JP, Hallett M (1999) A PET study of human auditory spatial processing. Neurosci Lett 262:155-158. CrossRef Medline

Werner-Reiss U, Groh JM (2008) A rate code for sound azimuth in monkey auditory cortex: implications for human neuroimaging studies. J Neurosci 28:3747-3758. CrossRef Medline

Wilke M, Holland SK, Altaye M, Gaser C (2008) Template-O-Matic: a toolbox for creating customized pediatric templates. Neuroimage 41:903913. CrossRef Medline

Withington-Wray DJ, Binns KE, Dhanjal SS, Brickley SG, Keating MJ (1990) The maturation of the superior collicular map of auditory space in the guinea pig is disrupted by developmental auditory deprivation. Eur J Neurosci 2:693-703. CrossRef Medline

Wong DE (2012) Effects of unilateral and bilateral cochlear implantation on cortical activity measured by an EEG neuroimaging method in children, $\mathrm{PhD}$ thesis. University of Toronto.

Wong DD, Gordon KA (2009) Beamformer suppression of cochlear implant artifacts in an electroencephalography dataset. IEEE Trans Biomed Eng 56:2851-2857. CrossRef Medline

Zatorre RJ, Penhune VB (2001) Spatial localization after excision of human auditory cortex. J Neurosci 21:6321-6328. Medline

Zatorre RJ, Ptito A, Villemure JG (1995) Preserved auditory spatial localization following cerebral hemispherectomy. Brain 118:879-889. CrossRef Medline 